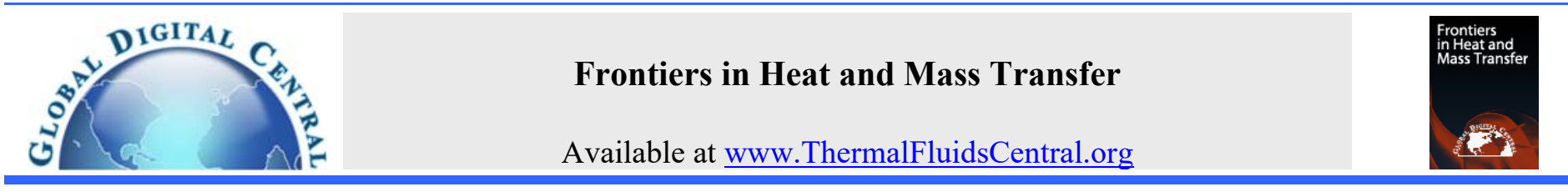

\title{
EFFECT OF LOCATION IN TRANSVERSE PLANE FOR 45-DEGREE V-BAFFLE ON FLOW AND HEAT TRANSFER MECHANISMS IN A SQUARE CHANNEL
}

\author{
Amnart Boonloi ${ }^{\mathrm{a}}$ and Withada Jedsadaratanachai ${ }^{\mathrm{b}, *}$ \\ ${ }^{a}$ Department of Mechanical Engineering Technology, College of Industrial Technology, King Mongkut's University of Technology North Bangkok, \\ Bangkok 10800, Thailand \\ ${ }^{b}$ Department of Mechanical Engineering, Faculty of Engineering, King Mongkut's Institute of Technology Ladkrabang, Bangkok 10520, Thailand
}

\begin{abstract}
Numerical predictions on flow and heat transfer in a square channel heat exchanger placed with V-baffle are examined. The gap spacing between the $\mathrm{V}$-baffle and channel wall is varied for all baffle heights. The laminar regime with $\mathrm{Re}=100-1000$ is considered. The numerical model for the square channel heat exchanger placed with V-baffle is validated. The preliminary result reveals that the computational domain has reliability to predict flow and heat transfer in the channel. The mechanisms on flow and heat transfer in the heat exchanger channel are illustrated at the numerical result section. The thermal performance analysis of the heating section when inserted with the V-baffle is also reported in forms of the Nusselt number ratio $\left(\mathrm{Nu} / \mathrm{Nu}_{0}\right.$ or $\left.\mathrm{Nu}\right)$, friction factor ratio $\left(\mathrm{f} / \mathrm{f}_{0}\right.$ or $\left.\mathrm{f}_{\mathrm{R}}\right)$ and thermal enhancement factor (TEF). As the results, it is found the gap spacing has extremely effect for flow structure and heat transfer behavior in the test section. The optimum gap spacing ratio may help to reduce the pressure loss or improves the heat transfer rate in the channel heat exchanger. The selection for the gap spacing ratio in the heating section at various baffle heights is also concluded. In addition, the gap spacing ratio around $5-10 \%$ is suggested for the range investigation.
\end{abstract}

Keywords: gap spacing; heat transfer; thermal performance; V-baffle; heat exchanger.

\section{INTRODUCTION}

From many researches about the augmentation on heat transfer rate of the heat exchanger system with vortex generators, it is found that the Vbaffle gives high efficiency to enhance heat transfer rate and thermal performance when compared with the other types. The cause is the $\mathrm{V}$ baffle can produce strong vortex flow and impinging flow in the test section. The vortex flow and impinging flow will disturb the thermal boundary layer on the heat transfer surface. The change of the thermal boundary layer is an important point for the increments of heat transfer rate and performance. Many researchers try to study about the mechanisms in the heating/cooling channel when varied the parameters of the vortex generators such as; flow attack angle, baffle height, baffle arrangements, pitch spacing, etc. The examples of the investigations on heat transfer rate and pressure loss of the heating system with vortex generators are briefed as follows;

Promvonge et al. (2012) numerically investigated a square channel placed with $45^{\circ} \mathrm{V}$-baffle on flow topology and heat transfer characteristics. The V-baffle placed on the opposite walls of the square channel with in-line arrangement and pointing downstream. The influences of the baffle height and baffle pitch were considered for laminar regime around $\mathrm{Re}=200-2000$. They reported the mechanisms in the heating duct and also concluded the performance of the baffled channel. They found that the baffled channel can develop the heat transfer rate and thermal performance than the smooth channel with no baffle. They stated that the optimum thermal performance around 3.8 is detected at blockage ratio and pitch spacing ratio of 0.2 and 1.5, respectively. Boonloi (2014) presented the numerical examine in a square duct that inserted with V-baffles. The influences of baffle height and baffle arrangement on heat transfer coefficient and pressure loss were considered for laminar flow with the Reynolds number around 100 - 2000. Boonloi (2014) reported that the optimum thermal performance is around 4.2, which is detected at blockage ratio of 0.20 and 0.15 for V-Downstream and V-Upstream, respectively. Boonloi and Jedsadaratanachai (2014) compared the different flow attack angles $\left(20^{\circ}, 30^{\circ}\right.$ and $\left.45^{\circ}\right)$ of the V-baffle in the square channel heat exchanger. The variations of the baffle height, baffle pitch, flow direction and arrangement were studied for laminar regime, $R e=100-2000$. They concluded that the thermal performance is about 4.25 at pitch-tochannel height of 1 , baffle height-to-channel height of $0.15, \mathrm{Re}=2000$ with V-Downstream and in-line arrangement. Li et al. (2018) simulated the thermal performance of a channel fitted with multi V-baffle for turbulent regime. They stated that the augmentation on the thermal performance is around $12 \%$ when placed the multi V-baffle in the channel heat exchanger. Boonloi and Jedsadaratanachai (2016) numerically investigated a square duct installed with discrete combined V-baffle and V-orifice (called "discrete combined baffle" or DCB). The flow visualization and heat transfer behavior in the baffled channel were shown. The parameters; DCB height and DCB position were considered for turbulent regime with the Re around $5000-20000$. They found that the vortex flow occurs through the test section when inserted with DCB in the channel. They also summarized that the heat transfer rate increases around $2.8-6$ times above the smooth channel with the maximum thermal performance factor around 1.72 .

*Corresponding author. Email: kjwithad@kmitl.ac.th 


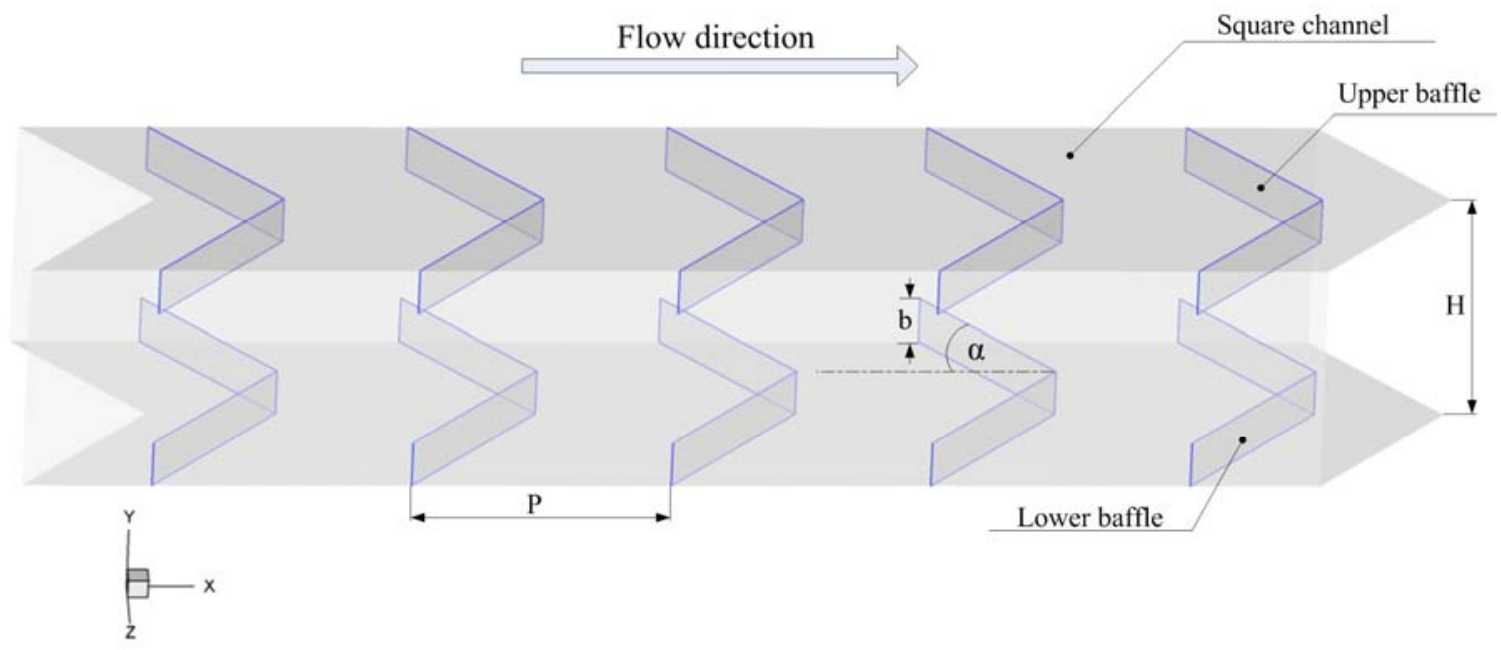

Fig. 1 Physical domain of the square channel placed with V-baffle.

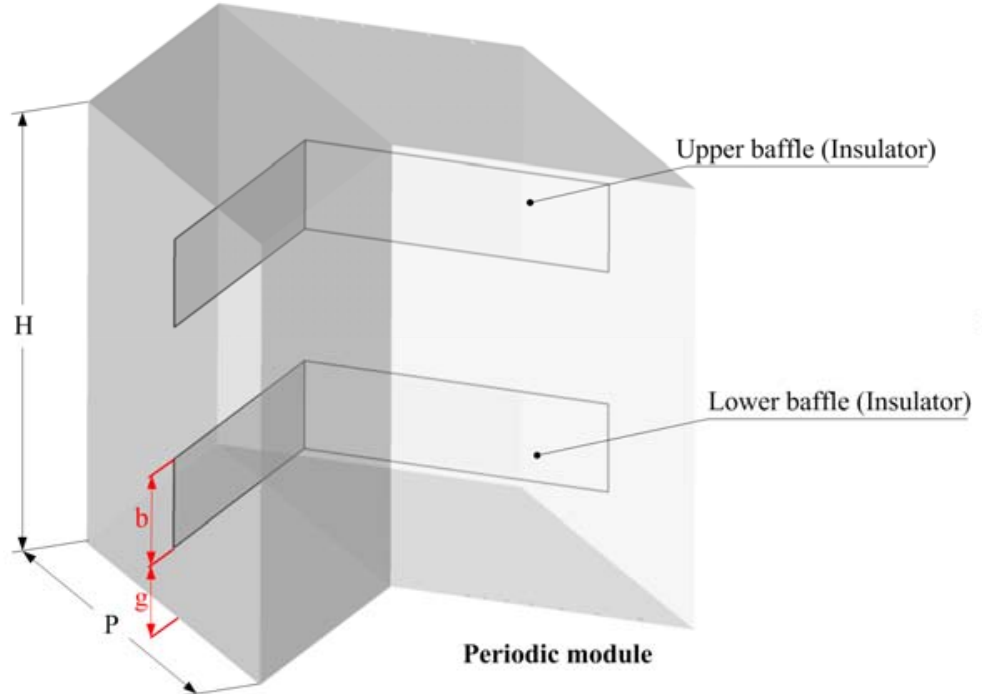

(a)

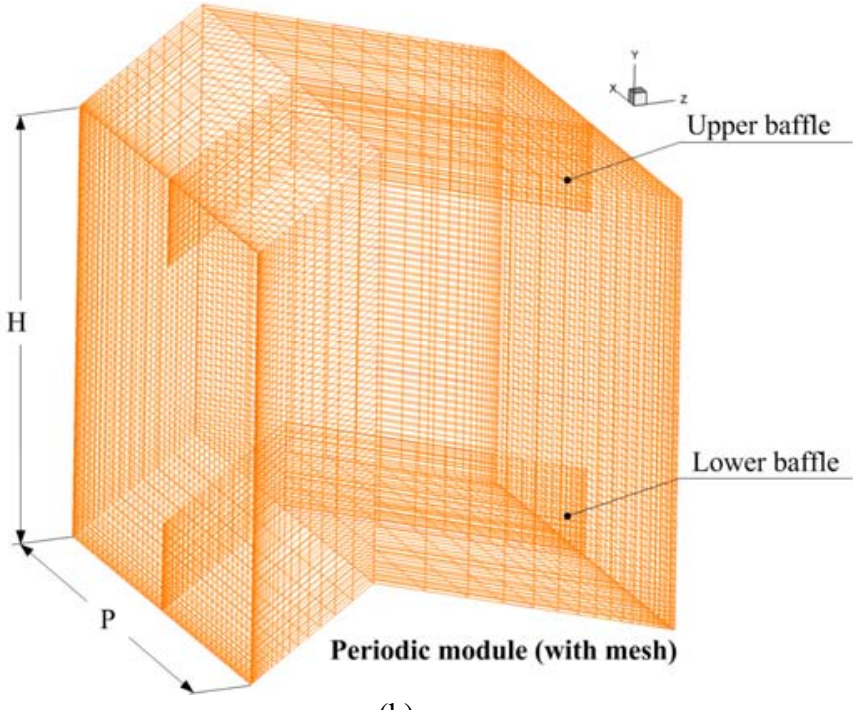

(b)

Fig. 2 (a) Computational module of the channel inserted with V-baffle and (b) computational module with mesh of the channel inserted with Vbaffle.

Kumar et al. (2017a) and Kumar et al. (2017b) experimentally examined the heat transfer rate and flow friction in a solar air heater channel with discretized broken V-baffle. The parameters of the baffled channel such as the relative baffle gap distance, relative baffle gap width, relative baffle height, relative baffle pitch and flow attack angle were studied for the Reynolds number from 3000 - 21000. They claimed that the discretized broken V-baffle performs higher thermal performance than the other types of the vortex generators. Jedsadaratanachai and Boonloi (2014) reported the investigations of a square channel placed with $30^{\circ}$ double V-baffles. They summarized that the optimal thermal performance is around 3.2, which is found at pitch spacing ratio, blockage ratio and Reynolds number of 1, 0.10 and 1200, respectively. Jedsadaratanachai et al. (2015) predicted the heat transfer rate and flow friction in a circular tube inserted with $45^{\circ} \mathrm{V}$-baffle. The effects of baffle height and flow direction were presented for laminar flow with $\mathrm{Re}=100-2000$. They detected that the maximum thermal enhancement factor is about 3.2 at the baffle height-to-tube diameter of 0.2 and 0.25 , respectively, for V-Upstream and V-Downstream. Promvonge (2010) illustrated that the multiple $60^{\circ} \mathrm{V}$-baffle in an $\mathrm{AR}=$ 10 channel, which gives the maximum thermal performance around 1.87 at $\operatorname{Re}=5000$ when considered at the baffle height-to-channel hydraulic diameter of 0.1. Kumar et al. (2016) studied the enhancement on heat transfer rate in a solar air heater channel that installed with broken multiple V-type baffle. The relative gap width of the baffled channel were varied for $\operatorname{Re}=3000-8000$. They pointed out that the best relative gap width is around 5. Promvonge and Kwankaomeng (2010) concluded that the optimum thermal performance is around 2.6 and 2.75 when inserted the $45^{\circ}$ staggered V-baffle in a square channel heat exchanger with baffle height-to-channel height of 0.15 and 0.2 at V-Upstream and V-Downstream, respectively.

As the literature reviews above, it is found the V-baffle gives high thermal performance when compared with the other types of the vortex generator. The parameters of the baffled channel such as baffle height, baffle pitch, flow attack angle, flow direction, etc., were investigated on both numerical and experimental studies. However, it is found the position in transverse plane of the V-shaped baffle in the channel has not been reported. Therefore, the numerical investigation on mechanisms in the square channel inserted with various positions in transverse plane of the V-baffle is presented in the current work. The position of the V-baffle may be an important factor for the changes of flow friction and heat transfer distribution of the baffled channel. 


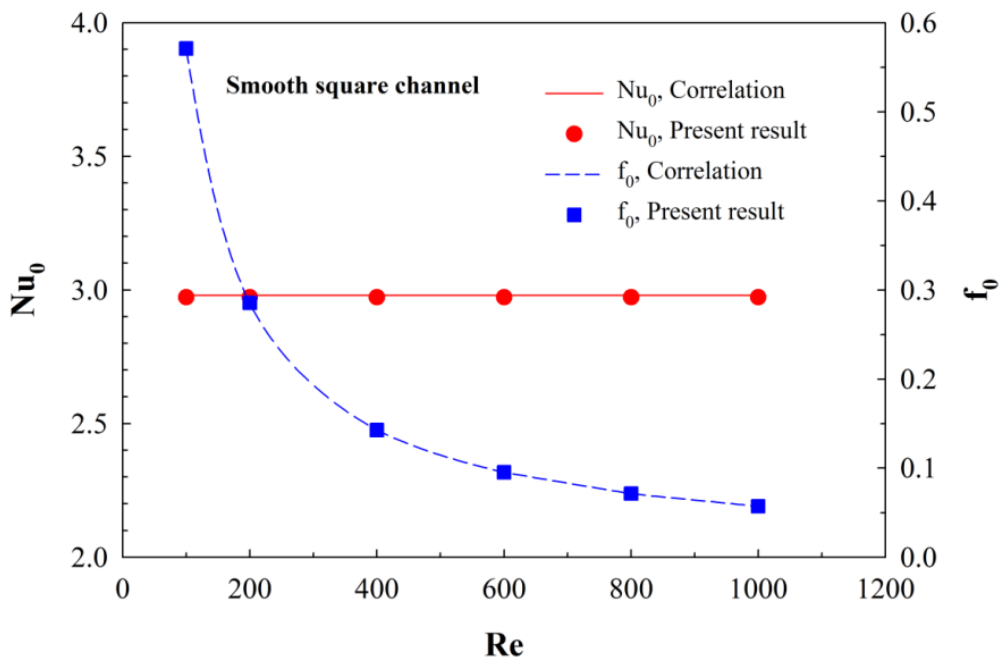

Fig. 3 Validation of the smooth square channel.

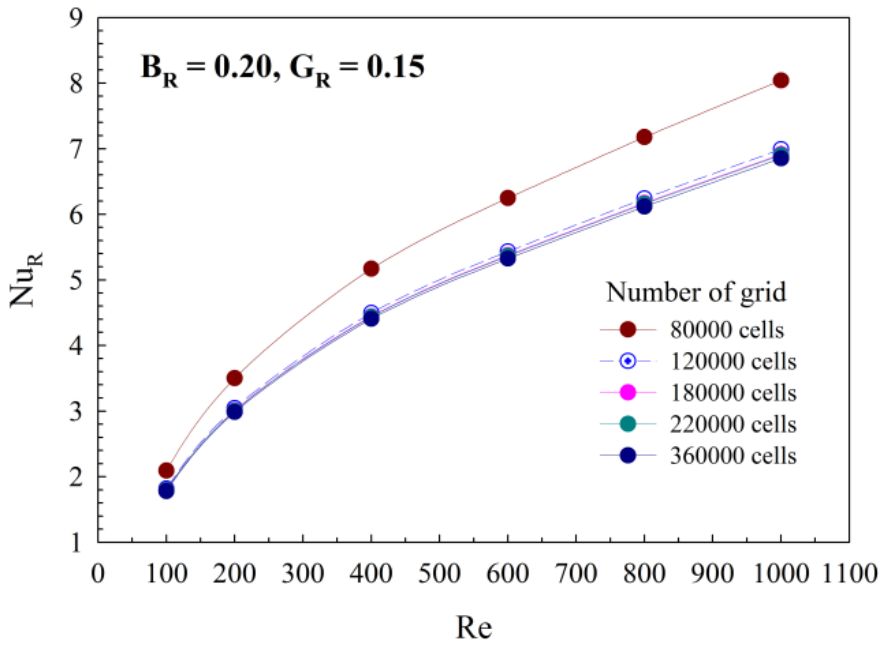

(a)

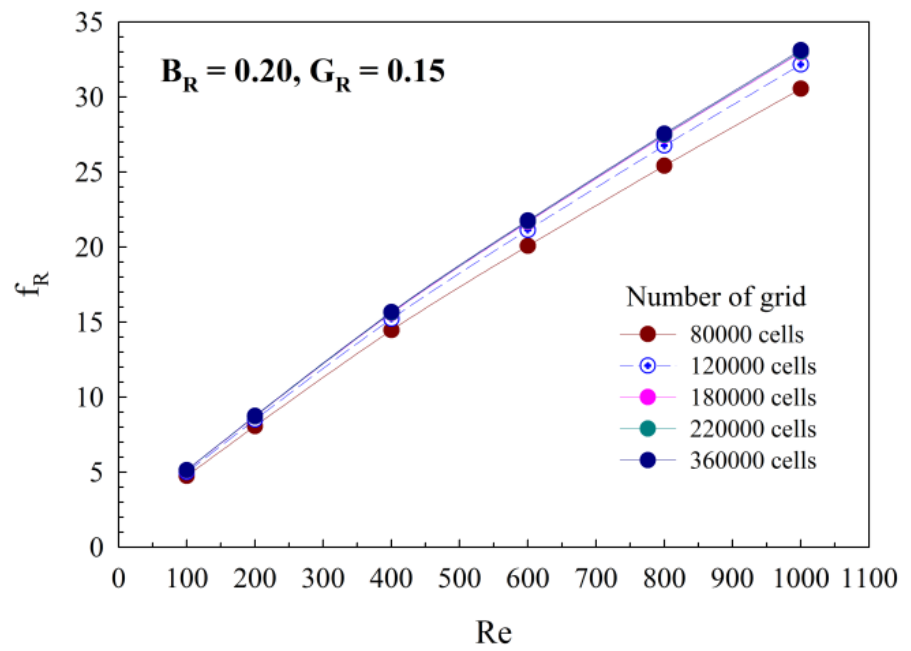

(b)

Fig. 4 Grid independence for (a) $\mathrm{NuR}$ and (b) $\mathrm{f}_{\mathrm{R}}$ at $\mathrm{B}_{\mathrm{R}}=0.20$ and $\mathrm{G}_{\mathrm{R}}=0.15$.

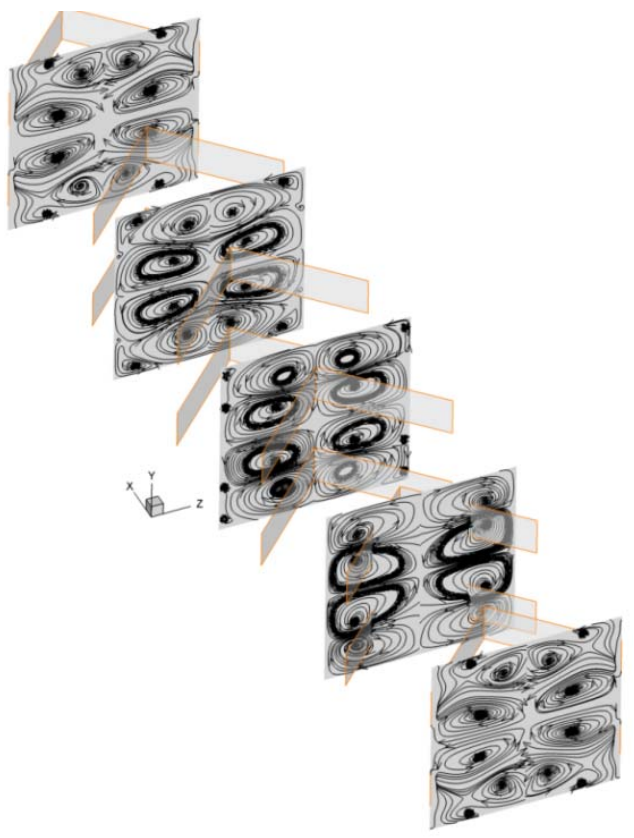

(a)

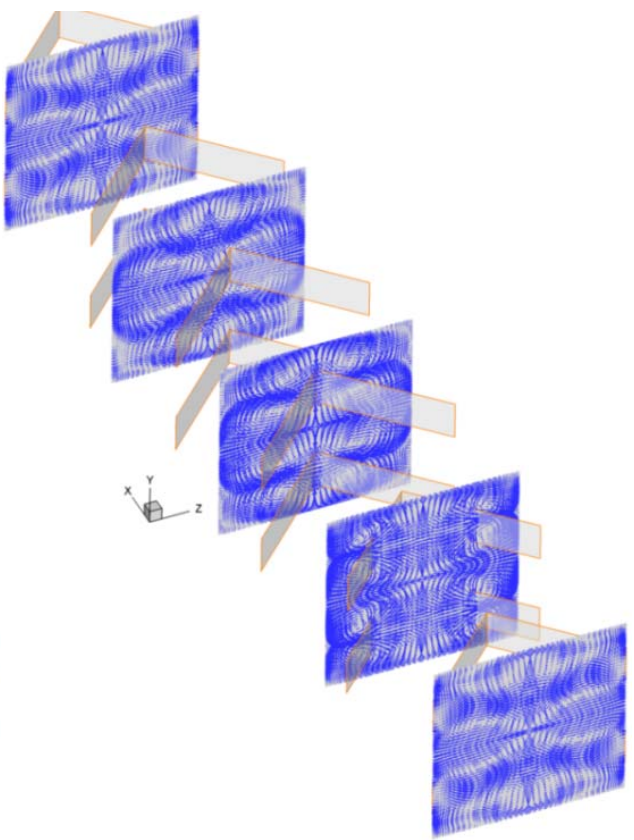

(b)

Fig. 5 Flow structure of the square channel inserted with V-baffle in term of (a) streamline in transverse planes and (b) tangential velocity vector in transverse planes at $\mathrm{B}_{\mathrm{R}}=0.20, \mathrm{G}_{\mathrm{R}}=0.15$ and $\mathrm{Re}=1000$. 


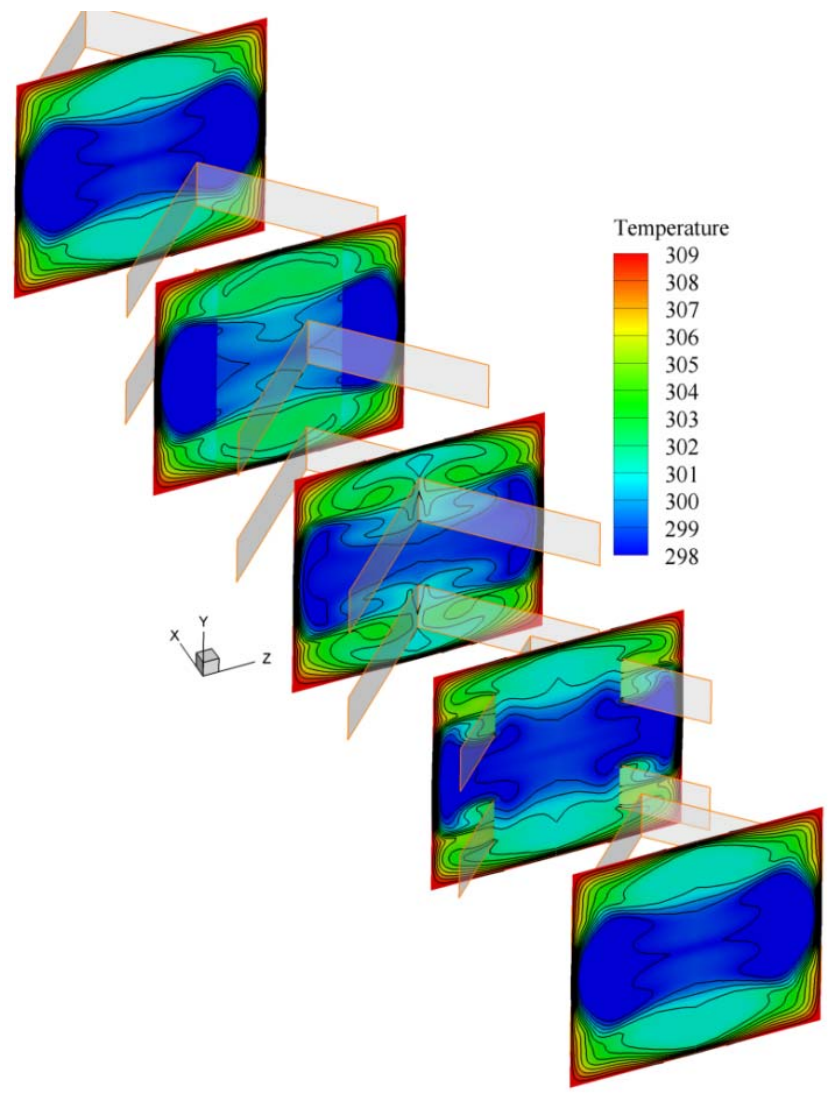

Fig. 6 Heat transfer characteristic of the square channel inserted with V-baffle in term of temperature distribution in transverse planes at $B_{R}=0.20$, $\mathrm{GR}_{\mathrm{R}}=0.15$ and $\mathrm{Re}=1000$

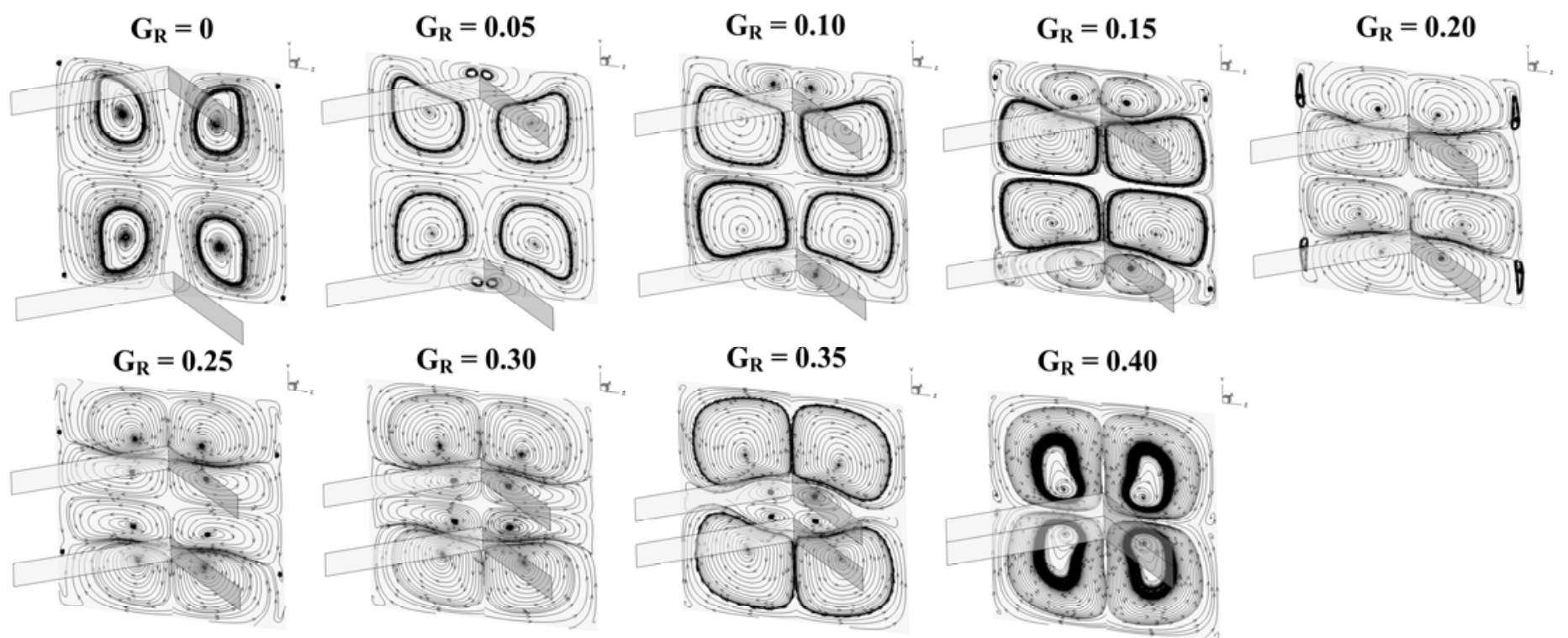

Fig. 7 Streamline in transverse planes for the square channel placed with V-baffle at various $\mathrm{G}_{\mathrm{R}}$ for $\mathrm{B}_{\mathrm{R}}=0.10$ and $\mathrm{Re}=600$.

\section{PHYSICAL MODEL AND BOUNDARY CONDITION}

The V-baffles are inserted in the square channel heat exchanger with Vapex pointing downstream. The square channel height, $\mathrm{H}$, equals to the channel width, W. The V-baffle can separate into two parts; upper and lower parts. The flow attack angle, $\alpha$, around $45^{\circ}$ of the V-baffle is selected for all examples. The spacing between leading edge of the $\mathrm{V}$ - baffle presents with $\mathrm{P}$, while the ratio of the pitch spacing and height of the square channel, $\mathrm{P} / \mathrm{H}$ or $\mathrm{P}_{\mathrm{R}}$ is fixed at 1 . The $\mathrm{b}$ is the baffle height, whiles the ratio of the $\mathrm{V}$-baffle height and square channel height, $\mathrm{b} / \mathrm{H}$ or $B_{R}$, is called blockage ratio. The blockage ratio of the present research is varied in the range around 0.05 to 0.30 . The physical geometry and parameters of the square channel heat exchanger installed with $\mathrm{V}$ baffles is illustrated as Fig. 1. 


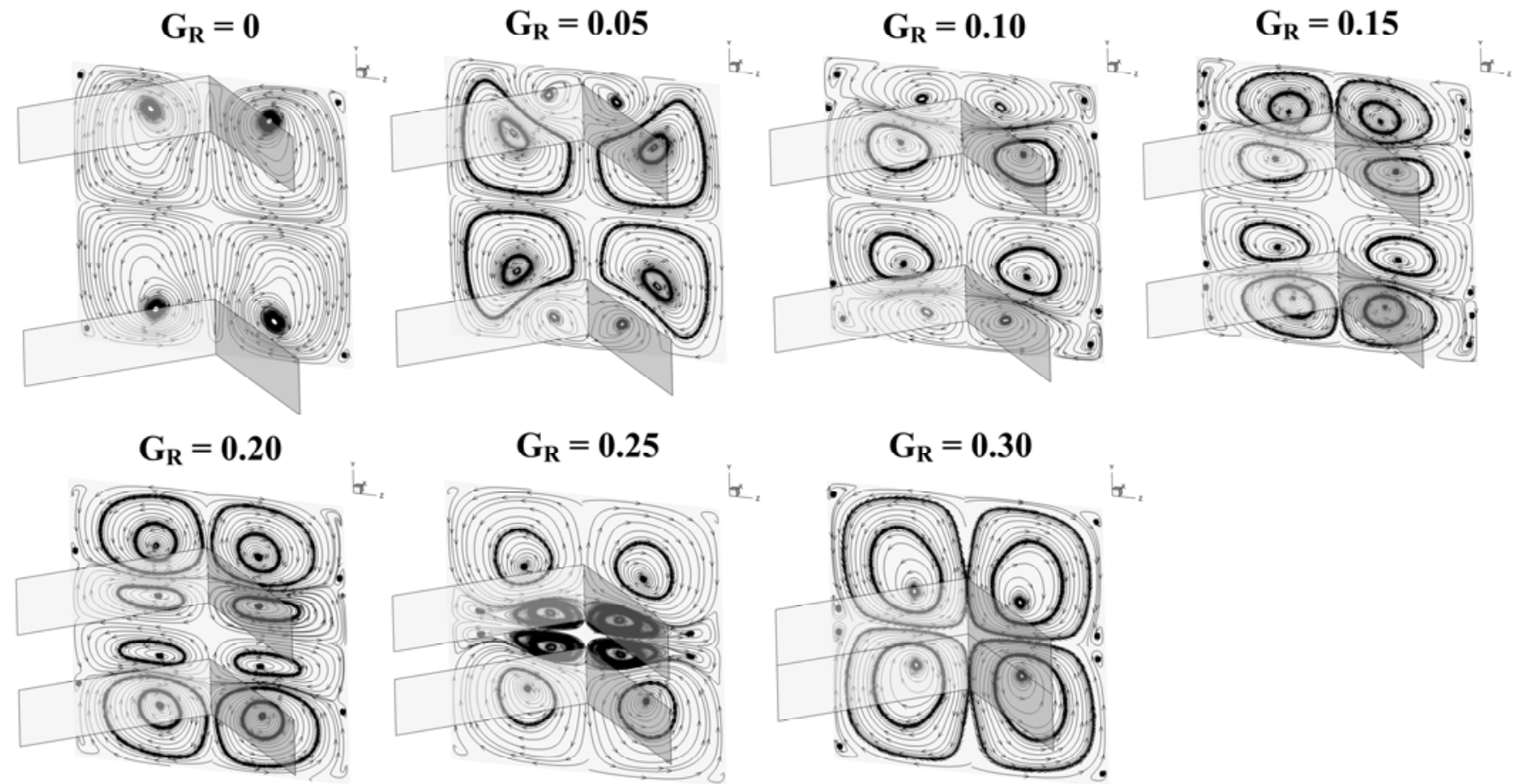

Fig. 8 Streamline in transverse planes for the square channel placed with V-baffle at various $G_{R}$ for $B_{R}=0.20$ and $R e=600$.

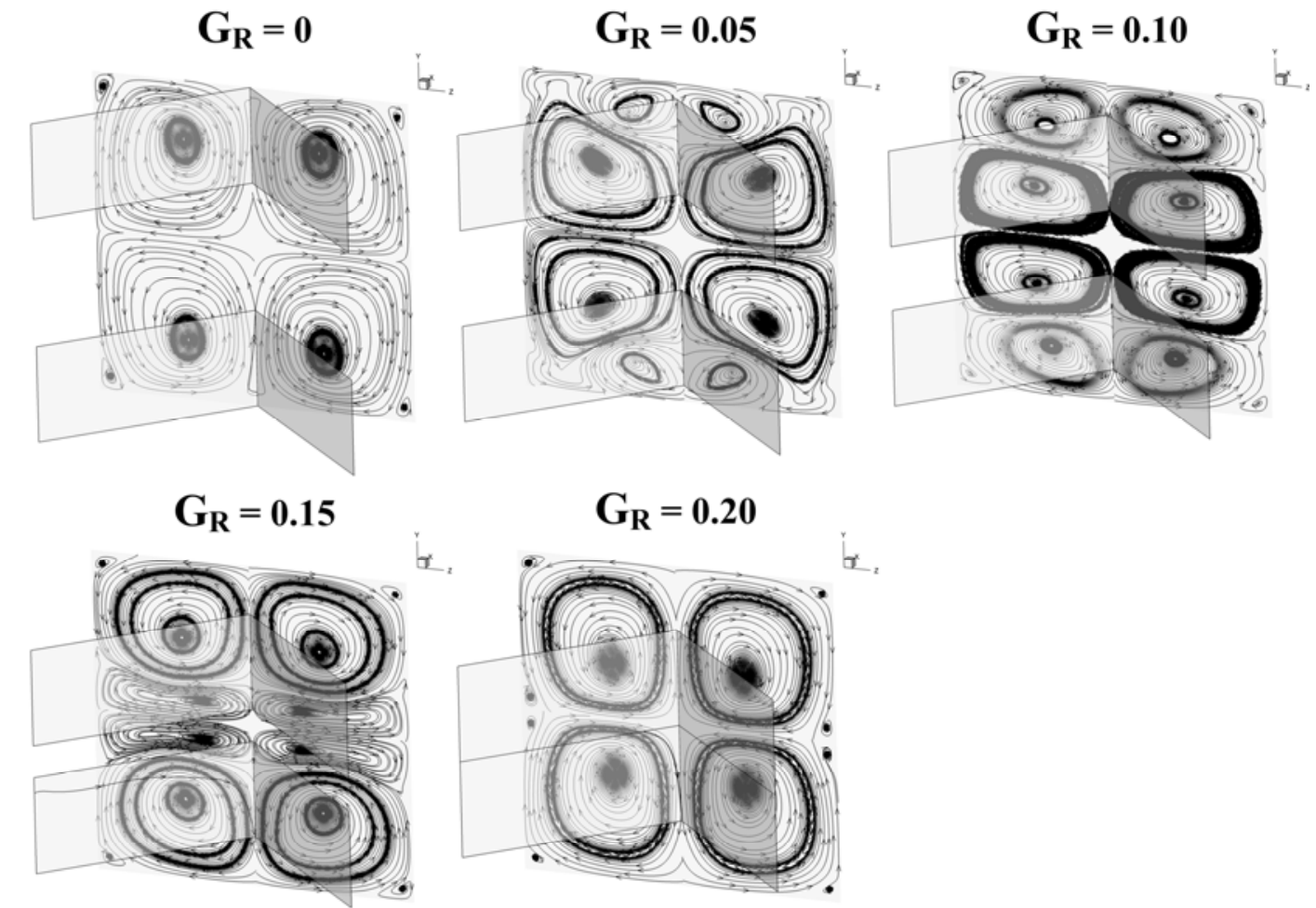

Fig. 9 Streamline in transverse planes for the square channel placed with V-baffle at various $\mathrm{G}_{\mathrm{R}}$ for $\mathrm{B}_{\mathrm{R}}=0.30$ and $\mathrm{Re}=600$.

g represents the gap spacing between the V-baffle and square channel wall. The ratio among the gap spacing and square channel height, $g / H$ or $\mathrm{G}_{\mathrm{R}}$, is named gap spacing ratio. The gap spacing ratio is varied around $0-0.45,0-0.40,0-0.35,0-0.30,0-0.25,0-0.20$ for the blockage ratio of $0.05,0.10,0.15,0.20,0.25$ and 0.30 , respectively. The periodic module of the square channel heat exchanger placed with $\mathrm{V}$ baffles is plotted as Fig. 2.

The periodic condition is set for the inlet and outlet of the computational domain. The constant temperature around $310 \mathrm{~K}$ is applied for all channel walls of the model. The V-baffle is assumed to be insulator. No slip wall condition is applied for all surfaces of the computational domain.

\section{ASSUMPTION AND MATHEMATICAL FOUNDATION}

The assumption of the present investigation for the square channel placed with V-baffle at various $G_{R}$ and $B_{R}$ values is illustrated as follows; 
- The test fluid is air at laminar flow region with the Reynolds number from 100 to 1000 . The incompressible condition is applied for the test fluid.

- The fluid flow and heat transfer are steady in three dimensions.

- The thermal properties of the test fluid (air with Prandtl number around 0.707 ) are approximated to be constant at the average bulk mean temperature around $300 \mathrm{~K}$.

- The convective heat transfer is measured, while the natural convection, body force, viscous dissipation and radiation heat transfer are disregarded.

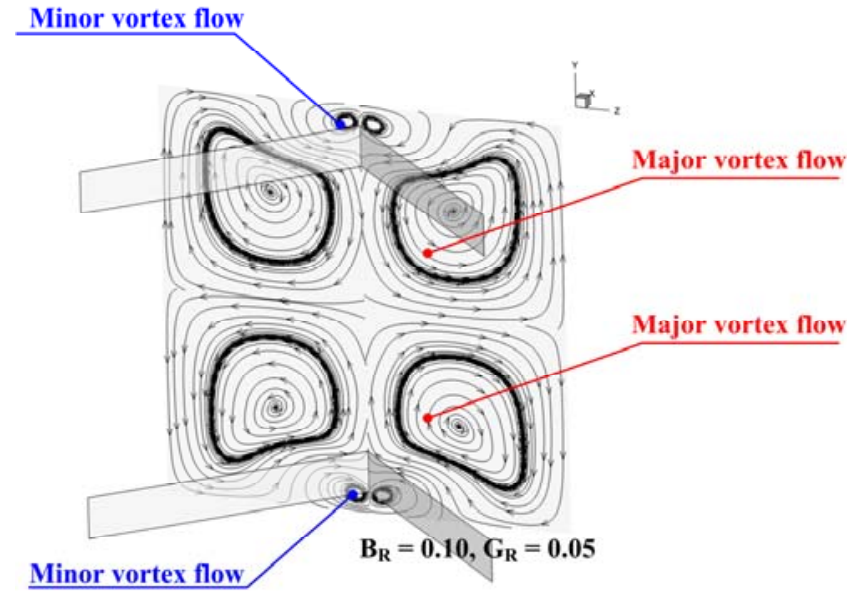

Fig. 10 Detail of flow structure in transverse planes for the square channel heat exchanger placed with V-baffle.

The heat exchanger channel equipped with the V-shaped baffle is governed by the continuity, the Navier-Stokes equations and the energy equation. The energy equation is discretized by the QUICK scheme, while the governing equations are discretized by power law scheme. The investigation on heat transfer and flow pattern in the heat exchanger duct equipped with the V-shaped baffle is resolved by finite volume method with SIMPLE algorithm. The solutions are considered to be converged when the normalized residual values are less than $10^{-5}$ for all variables, but less than $10^{-9}$ only for the energy equation. The commercial code (FLUENT) is selected for the present study.

In the Cartesian tensor form the continuity, the Navier-Stokes equations and the energy equation can be printed as follows:

Continuity equation:

$\frac{\partial}{\partial \mathrm{x}_{\mathrm{i}}}\left(\rho \mathrm{u}_{\mathrm{i}}\right)=0$

Momentum equation:

$\frac{\partial\left(\rho \mathrm{u}_{\mathrm{i}} \mathrm{u}_{\mathrm{j}}\right)}{\partial \mathrm{x}_{\mathrm{j}}}=-\frac{\partial \mathrm{p}}{\partial \mathrm{x}_{\mathrm{i}}}+\frac{\partial}{\partial \mathrm{x}_{\mathrm{j}}}\left[\mu\left(\frac{\partial \mathrm{u}_{\mathrm{i}}}{\partial \mathrm{x}_{\mathrm{j}}}+\frac{\partial \mathrm{u}_{\mathrm{j}}}{\partial \mathrm{x}_{\mathrm{i}}}\right)\right]$

Energy equation:

$\frac{\partial\left(\rho u_{\mathrm{i}} \mathrm{T}\right)}{\partial \mathrm{x}_{\mathrm{i}}}=\frac{\partial}{\partial \mathrm{x}_{\mathrm{j}}}\left(\Gamma \frac{\partial \mathrm{T}}{\partial \mathrm{x}_{\mathrm{j}}}\right)$

where, the thermal diffusivity, $\Gamma$, is written by

$\Gamma=\frac{\mu}{\operatorname{Pr}}$

The important parameters for the present investigation are reported in term of dimensionless variables. The velocity of the test fluid at the inlet is reported in terms of the Reynolds number.

The Reynolds number is calculated as:

$\operatorname{Re}=\rho \bar{u} D_{h} / \mu$
The pressure loss across the test section inserted with the V-baffle is concluded in term of the friction factor. The friction factor, $f$, is calculated from the pressure drop, $\Delta \mathrm{p}$, across the periodic module, $\mathrm{L}$.

$f=\frac{(\Delta p / L) D_{h}}{\frac{1}{2} \rho \bar{u}^{2}}$

The heat transfer rate is displayed in terms of local Nusselt number and average Nusselt number. The local heat transfer is measured by:

$N u_{x}=\frac{h_{x} D_{h}}{k}$

The average Nusselt number can be obtained by

$N u=\frac{1}{A} \int N u_{X} \partial A$

The thermal performance of the heating section when equipped with the V-baffle is presented in form of thermal enhancement factor. The thermal enhancement factor (TEF) is calculated by the augmentations on both heat transfer and friction factor at similar pumping power.

$T E F=\left.\frac{h}{h_{0}}\right|_{p p}=\left.\frac{N u}{N u_{0}}\right|_{p p}=\left(N u / N u_{0}\right) /\left(f / f_{0}\right)^{1 / 3}$

The $\mathrm{Nu}_{0}$ and $\mathrm{f}_{0}$ are the Nusselt number and friction factor for the smooth duct, respectively.

\section{NUMERICAL VALIDATION}

The computational model for the heat exchanger channel is verified. The grid independence and verification of the smooth square channel on heat transfer and friction loss are examined. The objective of the numerical validation is to increase the reliance of the numerical result.

Fig. 3 reports the relations of the $\mathrm{Nu}_{0}$ and $\mathrm{f}_{0}$ with the Reynolds number for the smooth square channel. The values from the present computational domain are compared with the values from the correlations for both Nusselt number and friction factor. As the figure, the variations of the Nusselt number and friction factor are around $0.5 \%$ and $0.7 \%$, respectively. The variations on both values is not more than $5 \%$, therefore the present computational domain has more reliability for predict flow and heat transfer mechanisms in the heat exchanger.

The numbers of grid around 80000, 120000, 180000, 220000 and 360000 for the computational domain at the case $\mathrm{B}_{\mathrm{R}}=0.20$ and $\mathrm{G}_{\mathrm{R}}=$ 0.15 are compared (see Fig. 4). It is found the augmentation of grid cell from 120000 to 180000 has no effect for heat transfer and pressure loss. Therefore, the present numerical model is created with the number of grid around 120000 for all examples. The optimum number of grid can help to reserve investigated time and computer resource.

\section{NUMERICAL RESULT}

\subsection{Flow and heat transfer mechanisms}

The general flow configuration in the channel that inserted with $\mathrm{V}$ baffles is presented with streamline in transverse planes and tangential velocity vector in transverse planes as depicted in Figs. 5a and b, respectively. The V-baffle with $B_{R}=0.20, G_{R}=0.15$ and $R e=1000$ is selected for these plots. As the figures, the vortex flow is found through the baffled channel in all cases. The V-baffle blocks the air flow and generates the vortex flow from the leading edges to the $\mathrm{V}$-apex. The core of the vortex flow has change depended on the location in the baffled channel. The creation of the vortex flow in the channel is an advantage for the heat transfer rate in the heating channel. The vortex flow likes as equipment which helps a better air mixing in the channel. The better mixing is reason for heat transfer improvement. The vortex flow is also a disruptor of the thermal boundary layer on the channel walls that is another cause for heat transfer and performance enhancement.

Fig. 6 illustrates the temperature distribution in transverse plane for the baffled channel at $\mathrm{B}_{\mathrm{R}}=0.2, \mathrm{G}_{\mathrm{R}}=0.15$ and $\mathrm{Re}=1000$. The 
temperature distribution is an indicator to check the fluid mixing in the channel heat exchanger. In general, the red layer of the hot fluid is found near the channel wall, while the blue layer of the cold fluid is detected at the center of the channel for the smooth square channel. The appearance of the V-baffle in the channel helps to reduce the hot layer near the channel wall and distributes the cold layer from the center of the square channel. The change of the temperature contour is a good sign for the improvement of the heat transfer rate in the channel.

The variations of the blockage ratio, gap spacing ratio and Reynolds number bring to the variances of the flow and heat transfer profiles. Generally, the changes of blockage ratio and Reynolds number leads to the change of vortex strength. The vortex strength increases when augmenting the baffle height and Reynolds number. The augmentations on the baffle height and Reynolds number not change the flow structure and heat transfer profile in the heating section, but the variance of the gap spacing ratio has extremely effect for the differences of flow and heat transfer profiles.
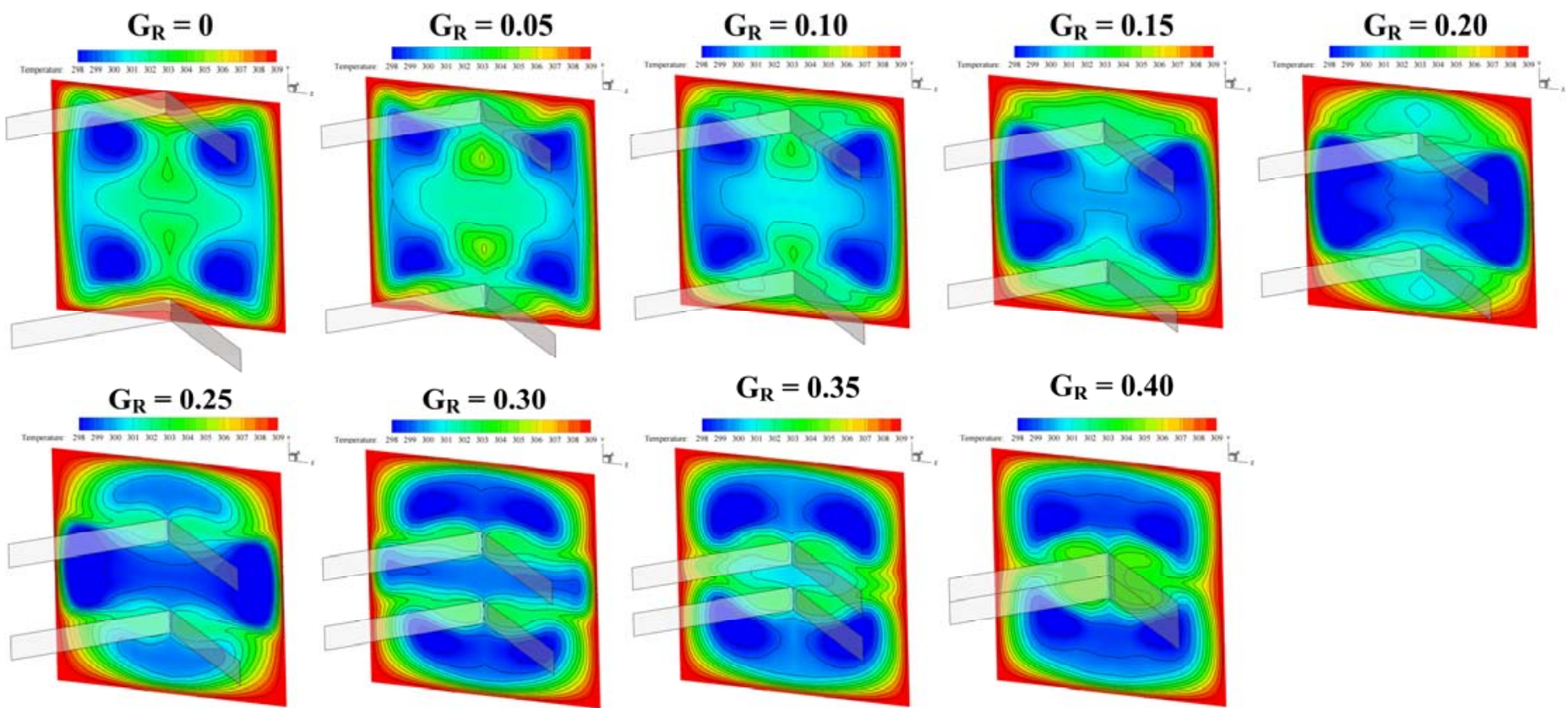

Fig. 11 Temperature contours in transverse planes for the square channel placed with V-baffle at various $G_{R}$ for $B_{R}=0.10$ and $R e=600$.
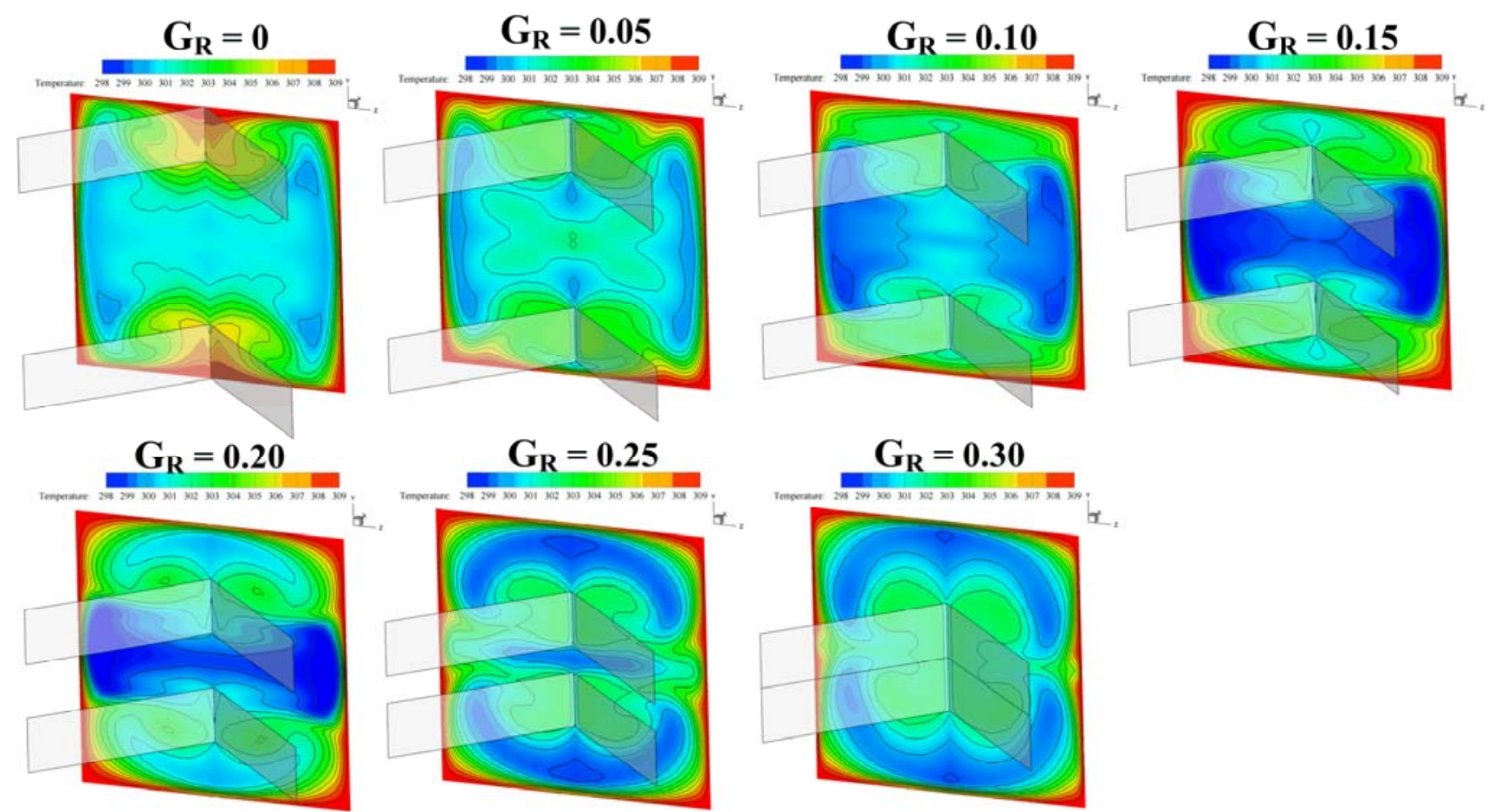

Fig. 12 Temperature contours in transverse planes for the square channel placed with V-baffle at various $G_{R}$ for $B_{R}=0.20$ and $R e=600$. 


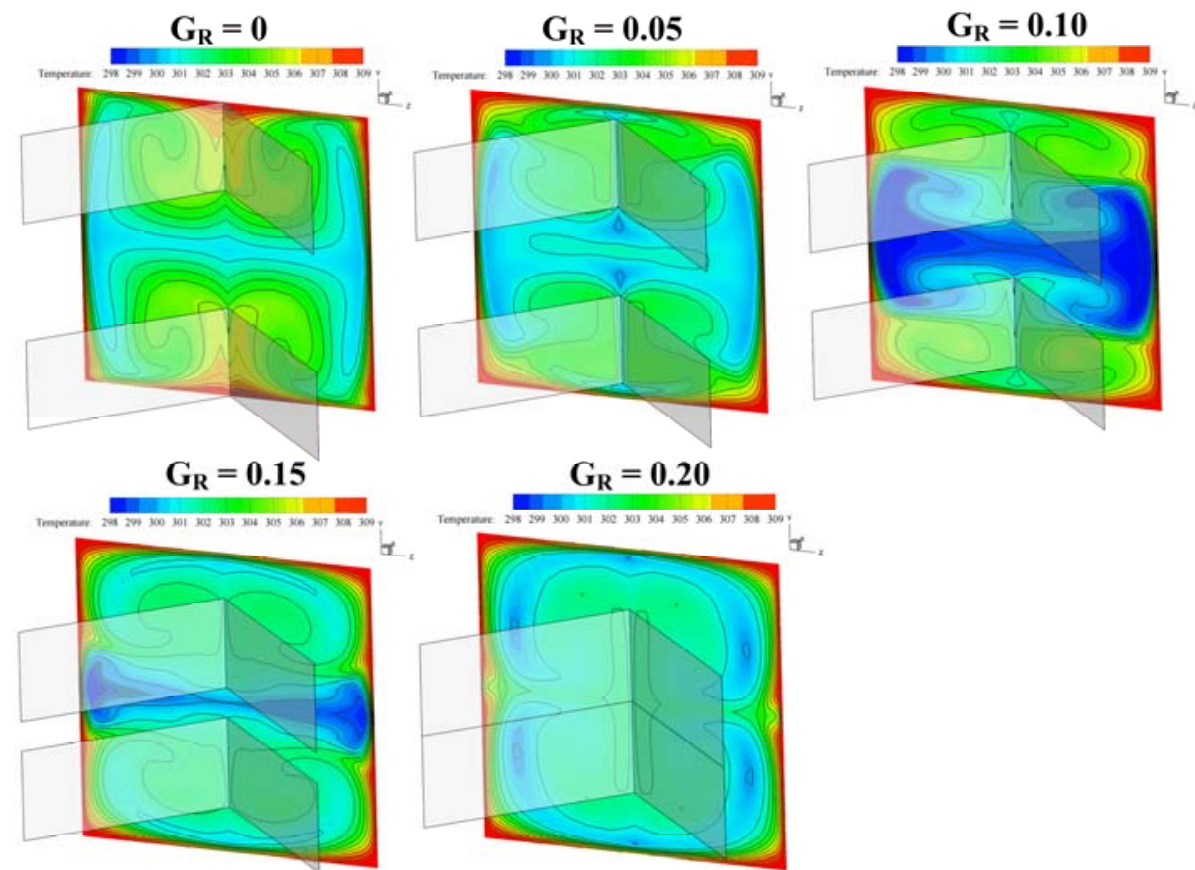

Fig. 13 Temperature contours in transverse planes for the square channel placed with V-baffle at various $G_{R}$ for $B_{R}=0.30$ and $R e=600$.
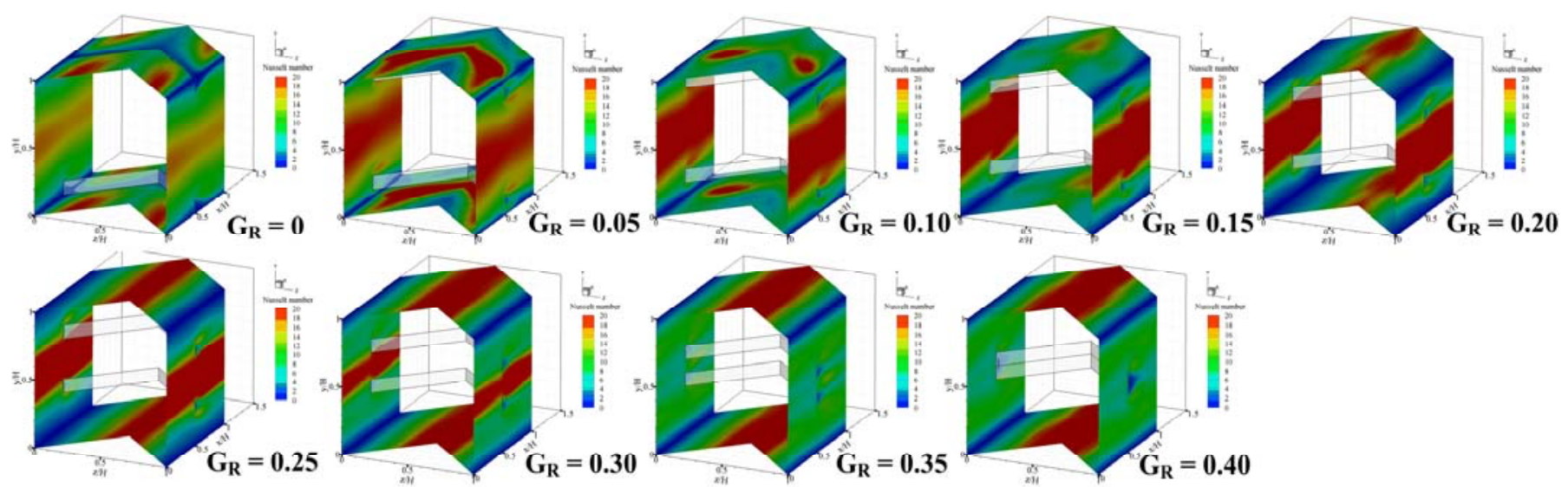

Fig. 14 Local Nusselt number contours in transverse planes for the square channel placed with V-baffle at various $G_{R}$ for $B_{R}=0.10$ and $R e=600$.
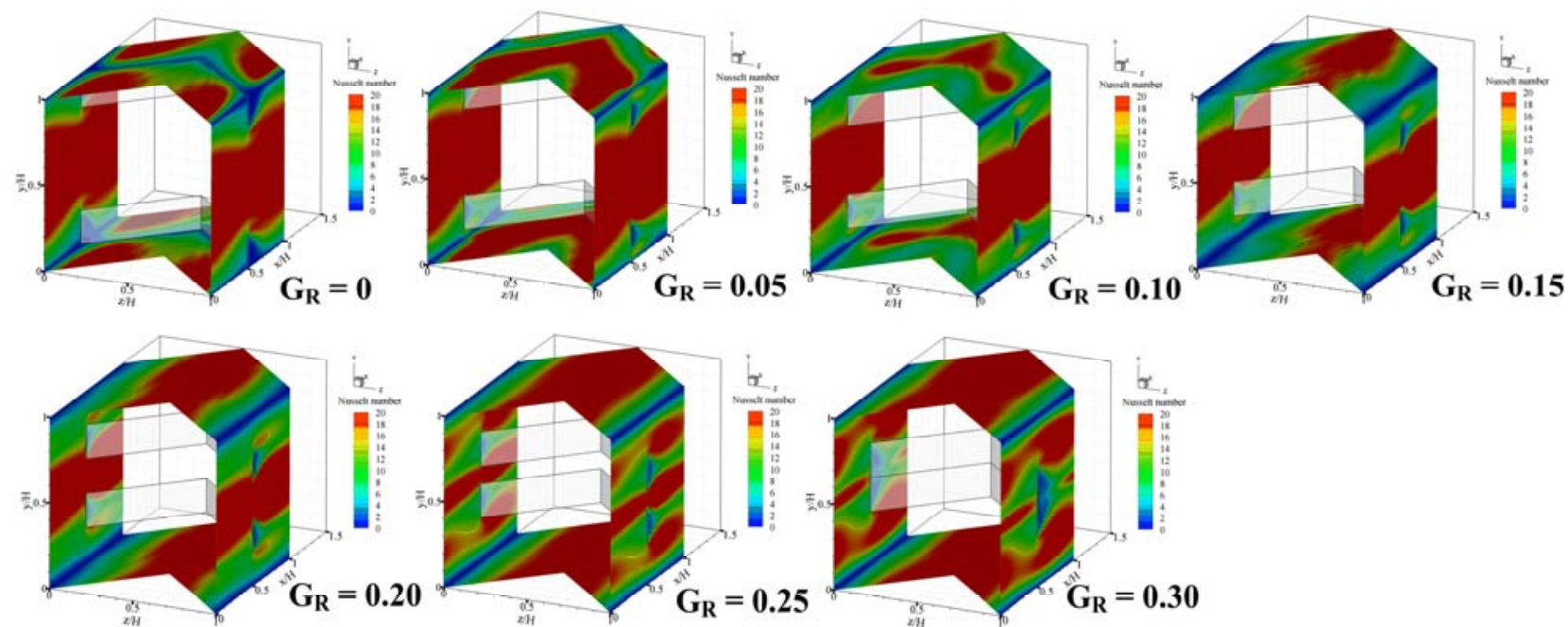

Fig. 15 Local Nusselt number contours in transverse planes for the square channel placed with V-baffle at various $G_{R}$ for $B_{R}=0.20$ and $R e=600$. 

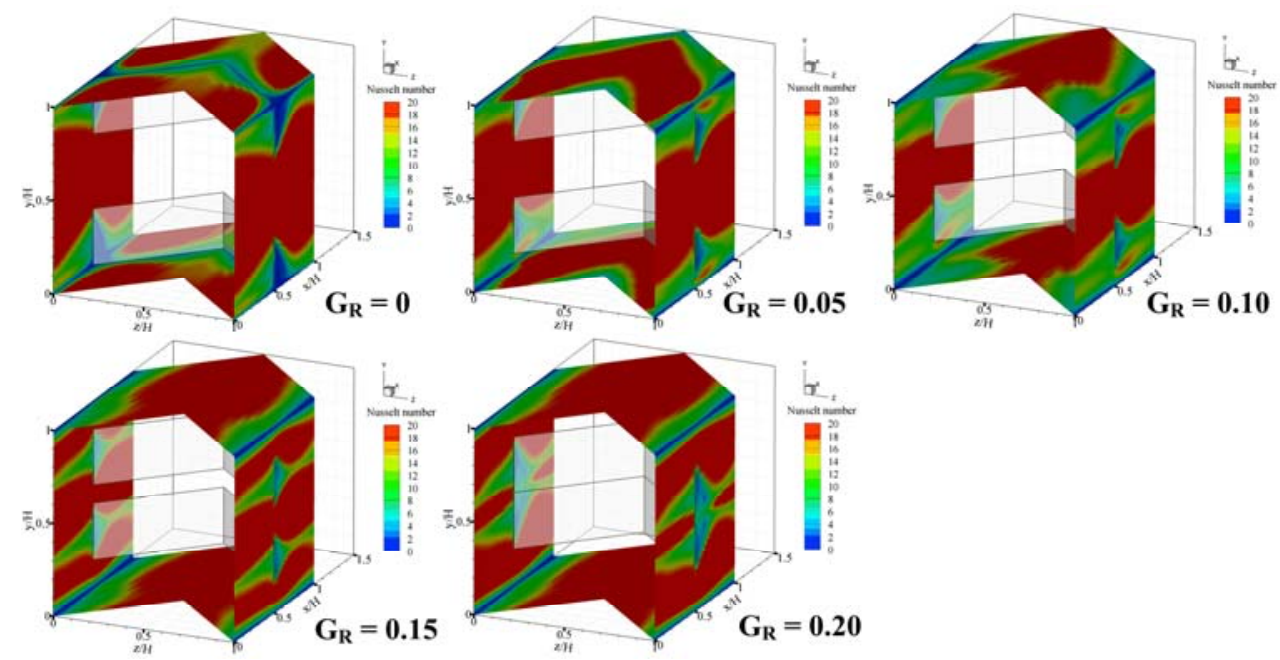

Fig. 16 Local Nusselt number contours in transverse planes for the square channel placed with V-baffle at various $G_{R}$ for $B_{R}=0.30$ and $R e=600$.

Figs. 7, 8 and 9 show the streamlines in transverse planes for the $\mathrm{B}_{\mathrm{R}}=$ $0.10,0.20$ and 0.30 of the V-baffles in the square channel, respectively, at $\mathrm{Re}=600$.

For $B_{R}=0.10$, the four main vortex flow is detected at $G_{R}=0$ (no gap). The symmetry flow at left and right parts is found due to the baffle symmetry. The V-baffle with zero gap spacing creates the counter rotating flow with common-flow-up (called "major vortex flow") when considering at the lower pair of the flow. The pair of small vortices (called "minor vortex flow") is found at the upper and lower parts of the plane where is near the $\mathrm{V}$-apex when $\mathrm{G}_{\mathrm{R}}=0.05$. The minor vortex flow is the counter vortex flow with common-flow-down when seeing at the lower pair. This means that the small gap at the upper and lower zones can produce the small vortices. The minor vortex flow performs larger when increasing $G_{R}$. The major vortex flow is not found in the case of $\mathrm{G}_{\mathrm{R}}=0.40$ value (like V-baffle inserted in the middle of the square channel). The similarly trend is detected in all blockage ratios when varied gap spacing ratio of the V-baffle in the channel. The flow description for the channel fitted with V-baffle is plotted as Fig. 10.

Figs. 11, 12 and 13 report the temperature contour in crosswise planes for the $\mathrm{B}_{\mathrm{R}}=0.10,0.20$ and 0.30 of the V-baffles in the test section with $\mathrm{Re}=600$, respectively. The V-baffles in the channel are as the thermal boundary layer interrupter. The disturbance of the thermal boundary layer in the heating section is a main reason for heat transfer and thermal performance improvement. The disruption of the thermal boundary regime can consider from the hot contour near the heat transfer surface. In this part, the red layer of the hot fluid near the four sides of the channels walls is focused.

For $B_{R}=0.10$, the thickness of the red layer is similarly found in the cases of $\mathrm{G}_{\mathrm{R}}=0-0.10$. The hot layer grows up when $0.15 \geq \mathrm{G}_{\mathrm{R}} \geq$ 0.30 , especially, at the four corners of the channel. The red contour slightly decreases when $\mathrm{G}_{\mathrm{R}}>0.30$. The maximum red layer thickness is detected for the $G_{R}=0.15$ and 0.10 for $B_{R}=0.20$ and 0.30, respectively. In addition, the increment of the baffle height can help to increase the vortex strength in the channel when observing the behavior of fluid mixing.

The local Nusselt number distribution on the channel walls inserted with $\mathrm{V}$-baffle at various gap spacing ratios is presented as Figs. 14,15 and 16 for $B_{R}=0.10,0.20$ and 0.30 , respectively, at $R e=600$. In general, the variation of the gap spacing ratio gives dissimilarly heat transfer configuration. The gap spacing between baffles and lowerupper walls of the channel has effect for heat transfer characteristic.

For $\mathrm{B}_{\mathrm{R}}=0.10$, the peak of heat transfer rate (red region) is found in all channel walls for $\mathrm{G}_{\mathrm{R}}=0$. The red region in all sides performs larger when $\mathrm{G}_{\mathrm{R}}=0.05$. The red layer of two sidewalls provides larger for $G_{R}=0.10$ and 0.15 , but tends to decrease for the upper and lower walls. In the range $0.20 \leq \mathrm{G}_{\mathrm{R}} \leq 0.30$, the red contour of the upper-lower walls performs larger, but lower for the left and right sidewalls. The red layer of the local Nusselt number is not detected in the cases of $G_{R}=$ 0.35 and 0.40 , while found only on the upper-lower zones of the channel. The similar trend of heat transfer profile with various gap spacing ratios is found when changes the blockage ratio of the V-baffle. Additionally, the enhancement of the blockage ratio for the V-baffle can augment the heat transfer rate.

\subsection{Performance analysis}

The Nusselt number ratio $\left(\mathrm{Nu} / \mathrm{Nu}_{0}, \mathrm{Nu}_{\mathrm{R}}\right)$, friction factor ratio $\left(\mathrm{f} / \mathrm{f}_{0}, \mathrm{f}_{\mathrm{R}}\right)$ and thermal enhancement factor (TEF) are plotted with the Reynolds number at various $B_{R}$ and $G_{R}$ values as depicted in Figs. 17, 18 and 19, respectively. The plots of $\mathrm{Nu}_{R}, f_{R}$ and TEF with $G_{R}$ at various $R e$ values are illustrated as the Figs. 20, 21, 22, 23, 24 and 25, for $B_{R}=0.05,0.10$, $0.15,0.20,0.25$ and 0.30 , respectively.

In general, the heat transfer rate enhances when increasing the Reynolds number due to the augmentation of the vortex strength in the test section. Almost cases, the placement of the V-baffle in the heating channel performs greater $\mathrm{Nu}_{\mathrm{R}}$ than the smooth channel with no baffle $(\mathrm{NuR}>1)$.

Considering at $\mathrm{Re}=1000, \mathrm{~B}_{\mathrm{R}}=0.05$, the peak of Nusselt number is about 3.97 times over the smooth channel which is detected at $\mathrm{G}_{\mathrm{R}}=$ 0.30 . The reason is the $\mathrm{G}_{\mathrm{R}}=0.30$ can produce the strongest vortex strength and also gives the best local Nusselt number distribution on the channel wall. The lowest value of heat transfer rate is found at $\mathrm{GR}_{\mathrm{R}}=$ 0.45 (the insertion in the middle of the square channel) when considering at $\mathrm{Re}=1000$. The $\mathrm{Nu}_{\mathrm{R}}$ for the heat exchanger channel fitted with V-baffle is around $0.99-3.30,1.01-3.67,1.02-3.44,1.04-$ $3.33,1.07-3.58,1.13-3.92,1.25-3.97,1.45-3.38,1.57-3.32$ and $1.53-3.28$ for the $\mathrm{GR}=0,0.05,0.10,0.15,0.20,0.25,0.30,0.35,0.40$ and 0.45 , respectively, at $\mathrm{BR}=0.05$.

For $\mathrm{B}_{\mathrm{R}}=0.10$ and $\mathrm{Re}=1000$, the maximum $\mathrm{Nu}_{\mathrm{R}}$ is around 5.98, which found at $\mathrm{G}_{\mathrm{R}}=0.05$, while $\mathrm{G}_{\mathrm{R}}=0$ gives the lowest heat transfer rate. The $\mathrm{Nu}_{\mathrm{R}}$ is around $1.02-4.14,1.11-5.98,1.16-4.74,1.21-$ $4.57,1.28-4.97,1.42-5.37,1.73-5.16,1.98-4.53$ and $1.97-4.87$, respectively, for $\mathrm{G}_{\mathrm{R}}=0,0.05,0.10,0.15,0.20,0.25,0.30,0.35$ and 0.40 .

Considering at $\mathrm{Re}=1000$ and $\mathrm{B}_{\mathrm{R}}=0.15$, the insertion of the Vbaffle in the test section can improve around $1.19-7.79$ times higher than the smooth channel. The maximum and minimum values of heat transfer rate are detected at gap spacing ratio around 0.05 and 0.15 , respectively, when regarding at $\mathrm{Re}=1000$. The $\mathrm{B}_{\mathrm{R}}=0.15$ of the Vbaffle with $\mathrm{G}_{\mathrm{R}}=0,0.10,0.15,0.20,0.25,0.30$ and 0.35 provides the $\mathrm{Nu}_{\mathrm{R}}$ around $1.19-6.75,1.45-7.79,1.45-6.17,1.49-5.99,1.63-$ $6.45,1.94-6.74,2.32-6.16$ and $2.29-6.57$, respectively, for the Reynolds number in the range $100-1000$. 


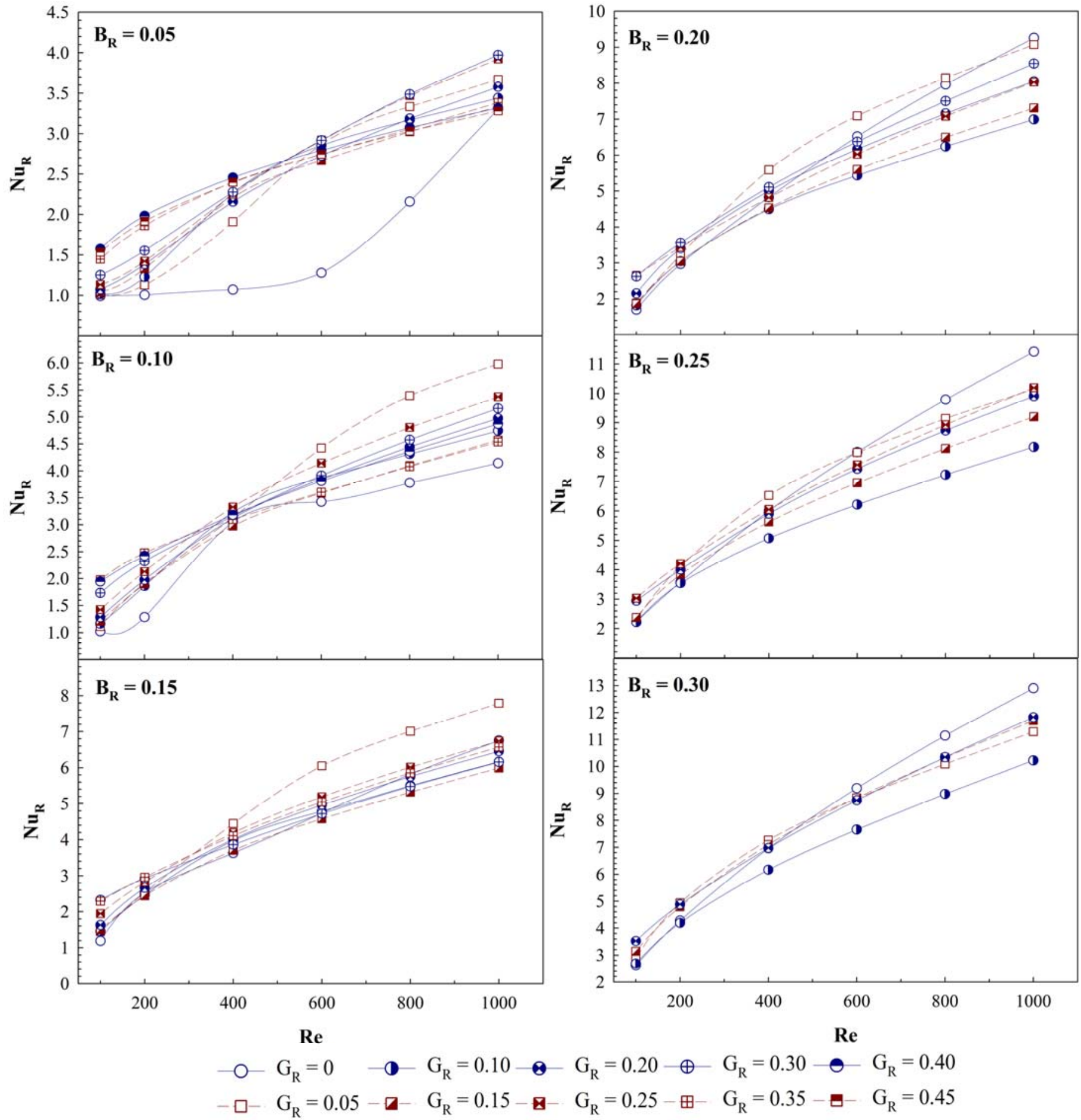

Fig. 17 The relation of the $\mathrm{Nu}_{R}$ with $\mathrm{Re}$ at various $\mathrm{B}_{\mathrm{R}}$ and $\mathrm{G}_{\mathrm{R} S}$ (data at $\mathrm{G}_{\mathrm{R}}=0$ is referred from Promvonge et al. (2012) and Boonloi (2014)).

The $\mathrm{B}_{\mathrm{R}}=0.20 \mathrm{~V}$-baffle can enhance heat transfer rate around $1.70-$ 9.26 times over the general channel with smooth surface. When considering at $\mathrm{Re}=1000$, the $\mathrm{GR}_{\mathrm{R}}=0$ and 0.10 gives the highest and lowest values of heat transfer rate, respectively. The $B_{R}=0.20 \mathrm{~V}$-baffle with $\mathrm{G}_{\mathrm{R}}=0,0.05,0.10,0.15,0.20,0.25$ and 0.30 operates the heat transfer rate greater than the smooth channel of about $1.70-9.26,1.89$ $-9.08,1.82-6.99,1.86-7.31,2.15-8.05,2.65-8.03$ and $2.62-$ 8.55 , respectively.

The improvement of heat transfer rate in the square channel fitted with the $\mathrm{B}_{\mathrm{R}}=0.25 \mathrm{~V}$-baffle over the smooth channel at $\mathrm{G}_{\mathrm{R}}=0,0.05$, $0.10,0.15,0.20$ and 0.25 is around $2.23-11.42,2.32-10.16,2.23-$
$8.18,2.38-9.20,2.98-9.91$ and $3.03-10.19$, respectively. The $\mathrm{G}_{\mathrm{R}}=$ 0 produce the beat heat transfer rate, while the reverse result is detected at $\mathrm{G}_{\mathrm{R}}=0.10$ when considering at the highest Reynolds number, $\mathrm{Re}=$ 1000 .

The $\mathrm{B}_{\mathrm{R}}=0.30 \mathrm{~V}$-baffle with the gap spacing ratio of $0,0.05,0.10$, 0.15 and 0.20 produces the heat transfer rate much more than the smooth channel around 2.61 - 12.90, $2.87-11.29,2.68-10.22,3.14-$ 11.7 and $3.52-11.82$, respectively. At $\mathrm{Re}=1000$, the optimum Nusselt number ratio is met at $\mathrm{G}_{\mathrm{R}}=0$, while the reverse trend is found at $\mathrm{G}_{\mathrm{R}}=$ 0.10 . 

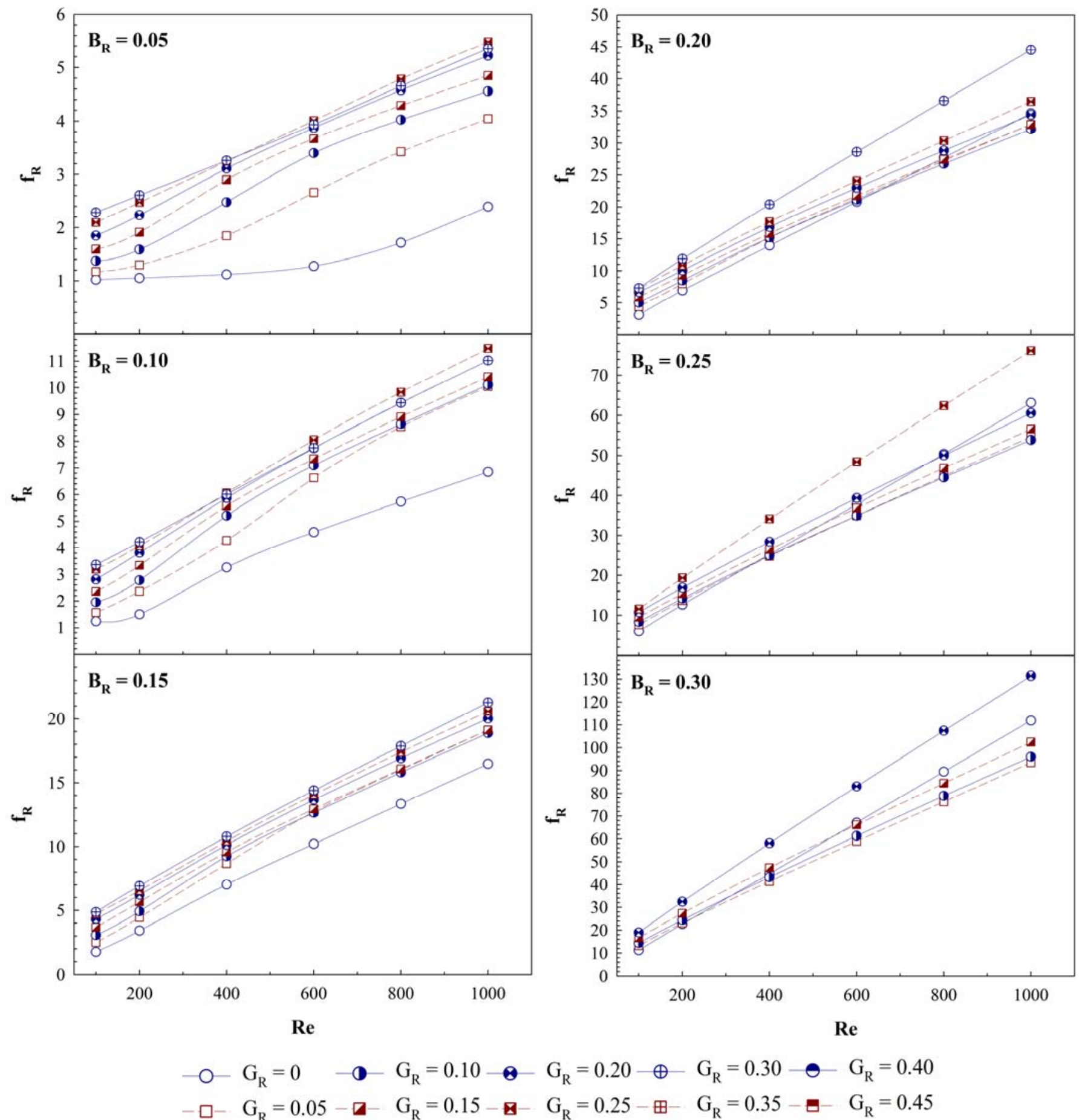

Fig. 18 The relation of the $f_{R}$ with Re at various $B_{R} S$ and $G_{R S}$ (data at $G_{R}=0$ is referred from Promvonge et al. (2012) and Boonloi (2014)).

The placement of the V-baffle in the square channel heat exchanger leads to enhance pressure loss higher than the smooth channel in all examples $\left(f_{R}>1\right)$. The gap spacing has effect for the increment or reduction of the pressure loss in the heating channel.

The $B_{R}=0.05$ of the V-baffle in the test section gives the $f_{R}$ around $1.02-2.39,1.17-4.04,1.37-4.56,1.59-4.85,1.85-5.22$, $2.10-5.48,2.28-5.35,2.34-4.82,2.30-4.90$ and $2.03-4.72$ for the $\mathrm{G}_{\mathrm{R}}=0,0.05,0.10,0.15,0.20,0.25,0.30,0.35,0.40$ and 0.45 , respectively, depended on the Reynolds number. The highest and lowest values of $f_{R}$ are found at $G_{R}=0$ and 0.40 , respectively, when considering at $\mathrm{Re}=1000$.

The $G_{R}$ of 0.40 performs the highest $f_{R}$ around 11.64, while $G_{R}=0$ provides the lowest value around 6.85 when considering at $\mathrm{B}_{\mathrm{R}}=0.10$ and $\operatorname{Re}=1000$. At $100 \leqslant \operatorname{Re} \leqslant 1000$, the friction loss in the square channel heat exchanger with $\mathrm{V}$-baffle at $\mathrm{B}_{\mathrm{R}}=0.10$ is greater than the smooth channel around $1.24-6.85,1.57-10.04,1.96-10.11,2.36-$ $10.41,2.81-11.02,3.19-11.47,3.36-11.02,3.34-11.00$ and $3.03-$ 11.64 , respectively, for $\mathrm{G}_{\mathrm{R}}=0,0.05,0.10,0.15,0.20,0.25,0.30,0.35$ and 0.40 . 

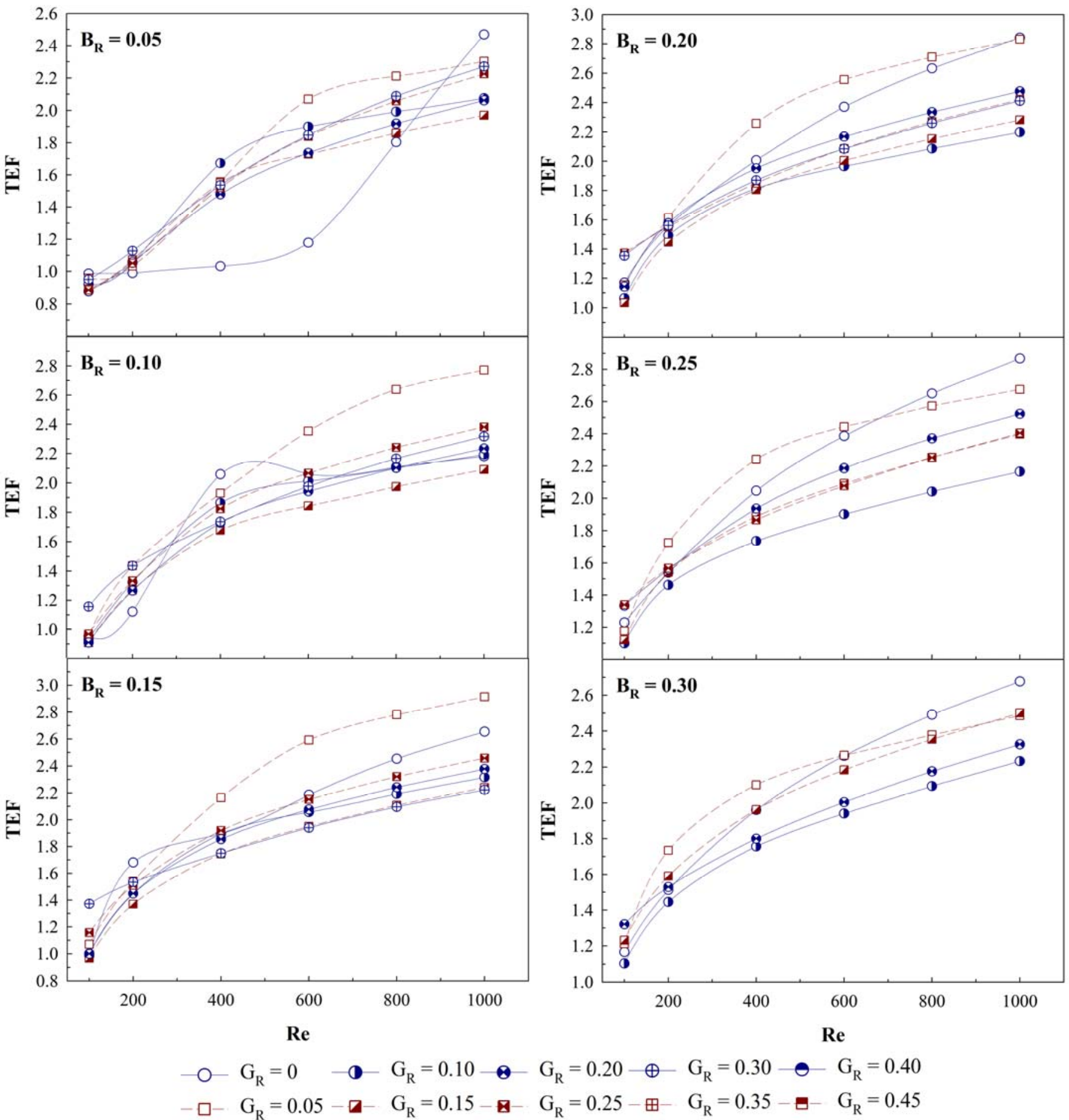

Fig. 19 The relation of the TEF with Re at various $\mathrm{B}_{\mathrm{RS}}$ and $\mathrm{GRS}_{\mathrm{RS}}$ (data at $\mathrm{GR}_{\mathrm{R}}=0$ is referred from Promvonge et al. (2012) and Boonloi (2014)).

The addition of the V-baffle in the square duct with the $\mathrm{B}_{\mathrm{R}}=0.15$ produces the friction loss much more than the smooth channel around 1.76 - 16.48, $2.49-19.12,3.06-18.87,3.67-19.11,4.32-20.02$, $4.72-20.58,4.86-21.27$ and $4.65-24.30$, respectively, when varying the $\mathrm{G}_{\mathrm{R}}$ of $0,0.05,0.10,0.15,0.20,0.25,0.30$ and 0.35 . At $\mathrm{Re}=1000$, the peak of $f_{R}$ is detected at $G_{R}=0.35$, while the opposite value is found at $\mathrm{G}_{\mathrm{R}}=0$.

Considering at $\mathrm{B}_{\mathrm{R}}=0.20$ and $\mathrm{Re}=1000$, it is found that the gap spacing ratio around $5-15 \%$ can help to decrease the pressure loss in the testing duct in comparison with the placement of the V-baffle on the channel wall $\left(\mathrm{G}_{\mathrm{R}}=0\right)$. The insertion of the $\mathrm{V}$-baffle in the middle of the square channel heat exchanger $\left(\mathrm{G}_{\mathrm{R}}=0.30\right)$ gives very large pressure loss around $7.29-44.50$ times above the smooth channel. The $\mathrm{B}_{\mathrm{R}}=$ 0.20 of the $\mathrm{V}$-baffle performs the friction factor ratio around 3.07 $34.64,4.36-32.94,4.99-32.15,5.85-32.87,6.66-34.41$ and $7.16-$ 36.48 for $\mathrm{G}_{\mathrm{R}}=0,0.05,0.10,0.15,0.20$ and 0.25 , respectively.

At $\mathrm{Re}=1000$ and $\mathrm{B}_{\mathrm{R}}=0.25$, the gap spacing ratio around $5-20 \%$ can reduce the pressure loss in the channel when compared with $\mathrm{G}_{\mathrm{R}}=0$. The high pressure loss is extremely detected at $\mathrm{G}_{\mathrm{R}}=0.25$ around 11.55 -76.20 times higher than the smooth duct. The $\mathrm{B}_{\mathrm{R}}=0.25$ of the V- 
baffle offers the $f_{R}$ around $5.98-63.09,7.63-54.70,8.31-53.91$, $9.54-56.57$ and $10.75-60.56$, respectively, for $\mathrm{G}_{\mathrm{R}}=0,0.05,0.10$, 0.15 and 0.20 .

The $f_{R}$ in the range $0.05 \leqslant G_{R} \leqslant 0.15$ appears to be lower than the $\mathrm{G}_{\mathrm{R}}=0$ and 0.20 when considering at $\mathrm{B}_{\mathrm{R}}=0.30$ and $\mathrm{Re}=1000$. The maximum friction factor is found at $\mathrm{G}_{\mathrm{R}}=0.20$ around 131.39 , while the opposite result is found at $\mathrm{GR}_{\mathrm{R}}=0.05$ around 93.47 when considering at the highest Reynolds number. The $f_{R}$ is around $11.27-111.88,13.29-$ $93.47,14.39-93.01,16.62-102.44$ and $18.93-131.39$, respectively, for $\mathrm{G}_{\mathrm{R}}=0,0.05,0.10,0.15$ and 0.20 at $\mathrm{B}_{\mathrm{R}}=0.30$.

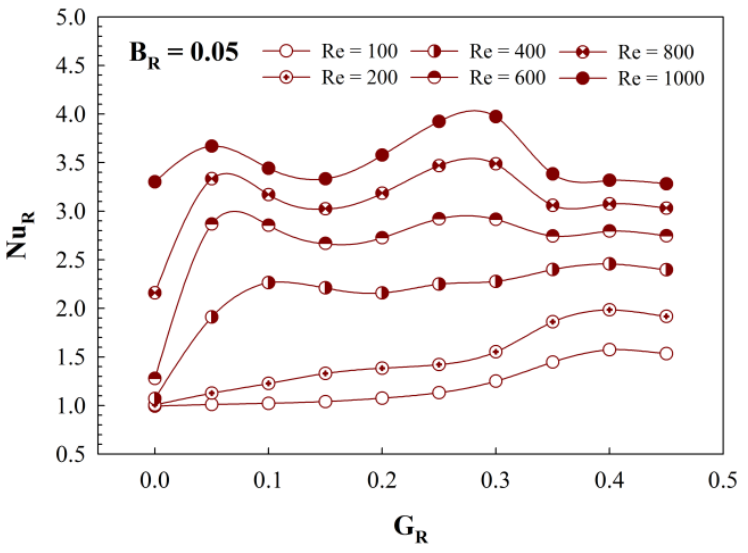

(a)

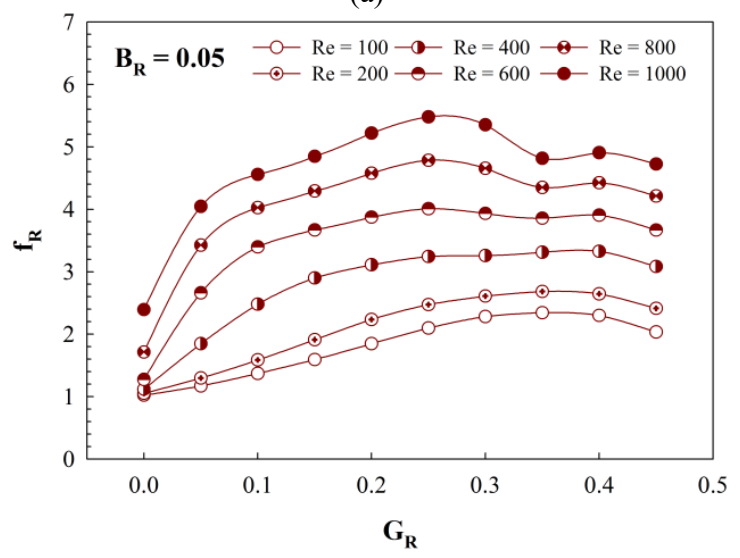

(b)

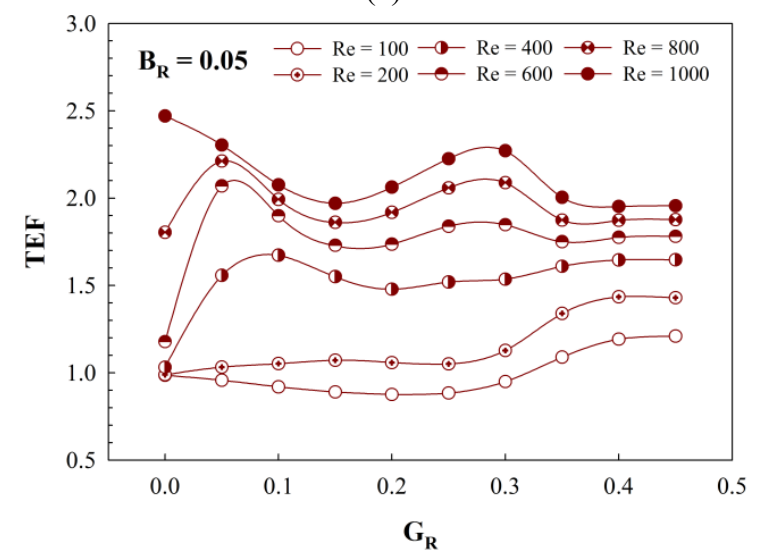

(c)

Fig. 20 (a) NuR vs $G_{R}$, (b) $f_{R}$ vs $G_{R}$ and (c) TEF vs $G_{R}$ for $B_{R}=0.05$ (data at $\mathrm{G}_{\mathrm{R}}=0$ is referred from Promvonge et al. (2012) and Boonloi (2014)).

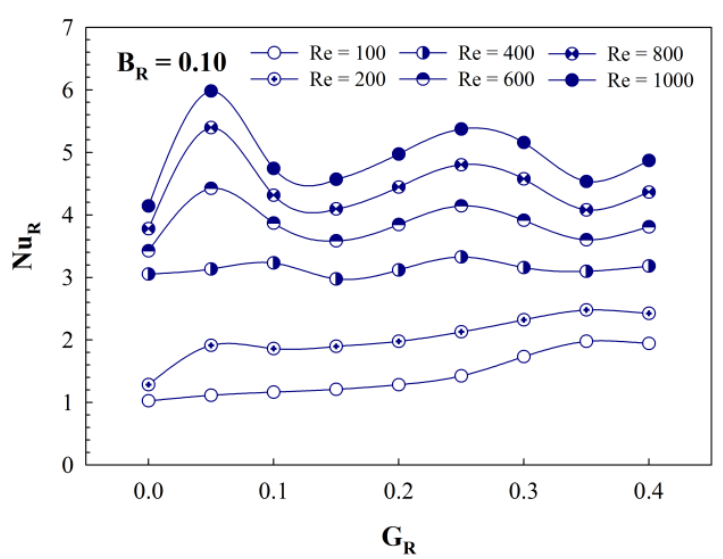

(a)

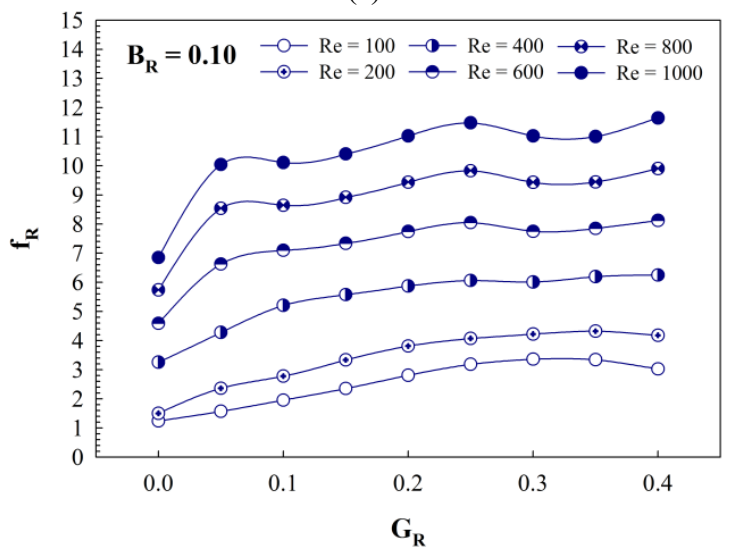

(b)

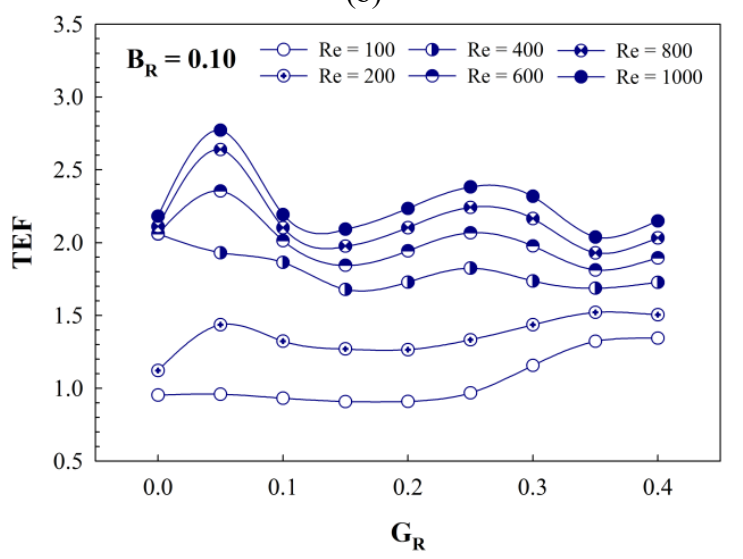

(c)

Fig. 21 (a) NuR vs $G_{R}$, (b) $f_{R}$ vs $G_{R}$ and (c) TEF vs $G_{R}$ for $B_{R}=0.10$ (data at $\mathrm{G}_{\mathrm{R}}=0$ is referred from Promvonge et al. (2012) and Boonloi (2014)).

The installation of the V-baffle in the square channel heat exchanger leads to upper both heat transfer rate and pressure loss. The augmentation of the heat transfer is an advantage for the heating system, while the enhancement of the pressure loss is not a benefit for the system. Therefore, the thermal efficiency of the heat exchanger placed with the V-baffle is concluded with the thermal performance at similar pumping power, which is called thermal enhancement factor or TEF.

The $\mathrm{B}_{\mathrm{R}}=0.05$ provides the optimum $\mathrm{TEF}$ at $\mathrm{G}_{\mathrm{R}}=0$ around 2.47. The TEF in the range $89-247 \%$ is detected when inserted V-baffle in the channel with $\mathrm{B}_{\mathrm{R}}=0.05$ depended on the Reynolds number and gap spacing ratio. The TEF is around $0.99-2.47,0.96-2.30,0.92-2.08$, $0.89-1.97,0.88-2.06,0.88-2.23,0.95-2.27,1.09-2.00,1.19-$ 
1.95 and $1.21-1.96$, respectively, for $\mathrm{G}_{\mathrm{R}}=0,0.05,0.10,0.15,0.20$, $0.25,0.30,0.35,0.40$ and 0.45 .

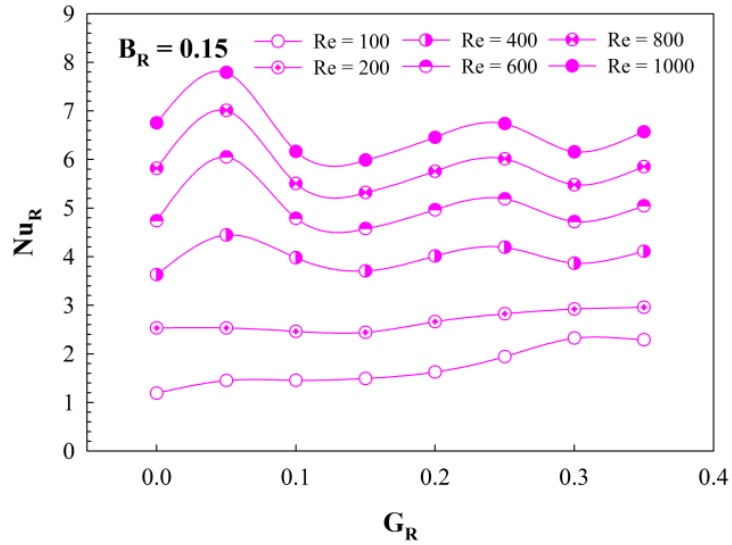

(a)

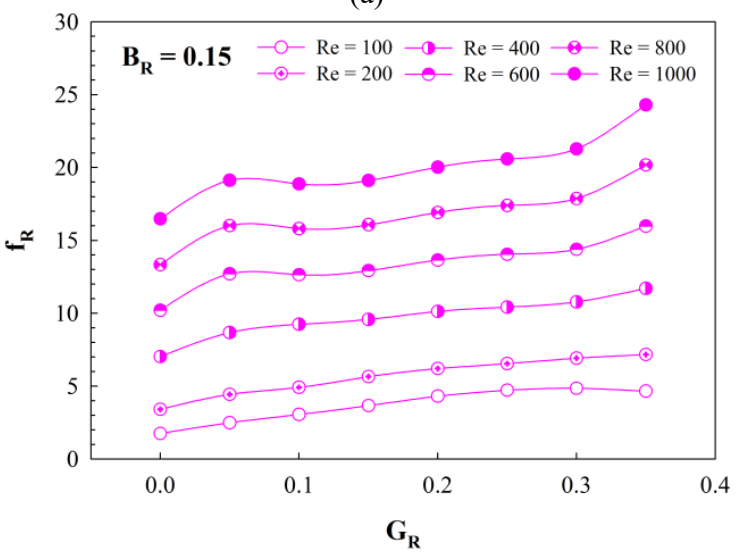

(b)

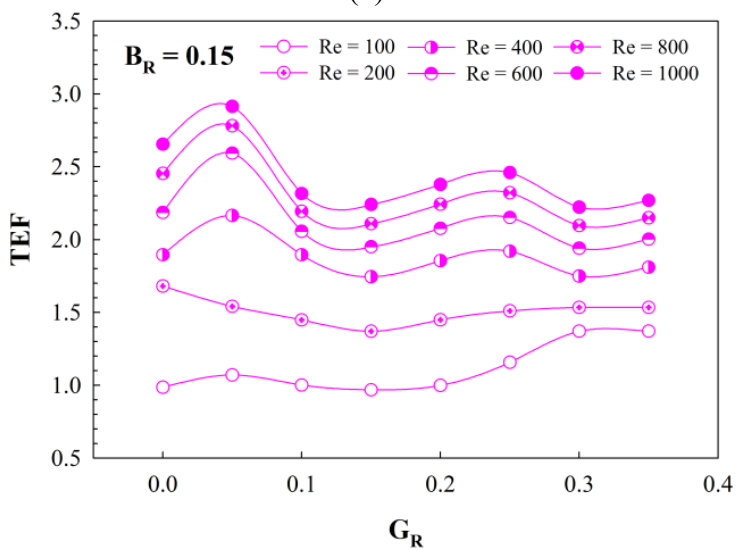

(c)

Fig. 22 (a) $\mathrm{Nu}_{\mathrm{R}}$ vs $\mathrm{G}_{\mathrm{R}}$, (b) $f_{R}$ vs $\mathrm{G}_{\mathrm{R}}$ and (c) TEF vs $\mathrm{G}_{\mathrm{R}}$ for $\mathrm{B}_{\mathrm{R}}=0.15$ (data at $G_{R}=0$ is referred from Promvonge et al. (2012) and Boonloi (2014)).

The highest TEF is around 2.77 which found at $\mathrm{G}_{\mathrm{R}}=0.05$ for $\mathrm{B}_{\mathrm{R}}=0.10$ and $\mathrm{Re}=1000$. The deposition of the $\mathrm{V}$-baffle with $\mathrm{B}_{\mathrm{R}}=0.10$ in the square channel performs the TEF about $0.95-2.18,0.96-2.77,0.93-$ $2.19,0.91-2.09,0.91-2.23,0.97-2.38,1.16-2.32,1.32-2.04$ and $1.34-2.15$ for $\mathrm{G}_{\mathrm{R}}=0,0.05,0.10,0.15,0.20,0.25,0.30,0.35$ and 0.40 , respectively.

The $\mathrm{B}_{\mathrm{R}}=0.15$ of the V-baffle offers the TEF in the range $0.99-$ $2.65,1.07-2.91,1.00-2.32,0.97-2.24,1.00-2.38,1.16-2.46$, $1.37-2.22$ and $1.37-2.27$, respectively, for $G_{R}=0,0.05,0.10,0.15$, $0.20,0.25,0.30$ and 0.35 . The optimum thermal enhancement factor is around 2.65 when inserting the V-baffle with $\mathrm{B}_{\mathrm{R}}=0.15, \mathrm{G}_{\mathrm{R}}=0$ at the highest Reynolds number.

At $\mathrm{Re}=1000$ and $\mathrm{B}_{\mathrm{R}}=0.20$, the maximum TEF is detected at $\mathrm{G}_{\mathrm{R}}$ $=0$ and 0.05 around 2.83. The $\mathrm{G}_{\mathrm{R}}=0,0.05,0.10,0.15,0.20,0.25$ and 0.30 of the V-baffle with $\mathrm{B}_{\mathrm{R}}=0.20$ performs the TEF around 1.17 $2.83,1.15-2.83,1.06-2.20,1.03-2.28,1.14-2.48,1.37-2.42$ and $1.35-2.41$, respectively.

For $\mathrm{B}_{\mathrm{R}}=0.25$, the TEF is around $1.23-2.87,1.18-2.68,1.10-$ $2.16,1.12-2.40,1.33-2.52$ and $1.34-2.40$, respectively for $\mathrm{G}_{\mathrm{R}}=0$, $0.05,0.10,0.15,0.20$ and 0.25 . The peak of thermal performance for the $\mathrm{B}_{\mathrm{R}}=0.25 \mathrm{~V}$-baffle is found at $\mathrm{G}_{\mathrm{R}}=0$ at the highest Reynolds number.

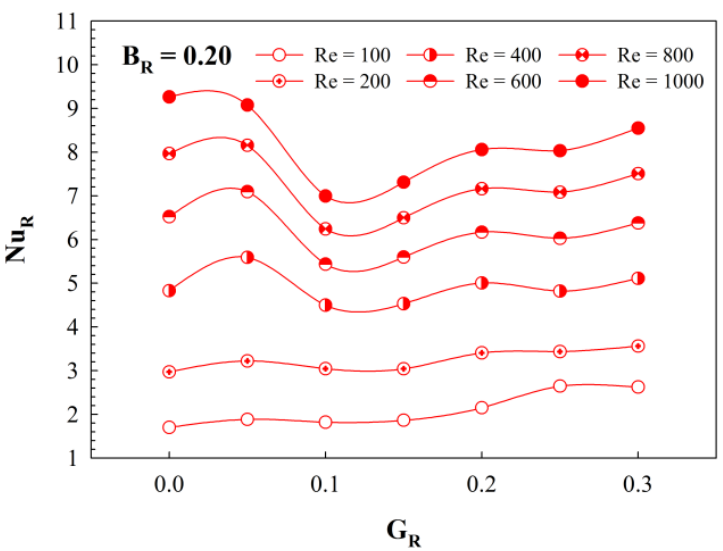

(a)

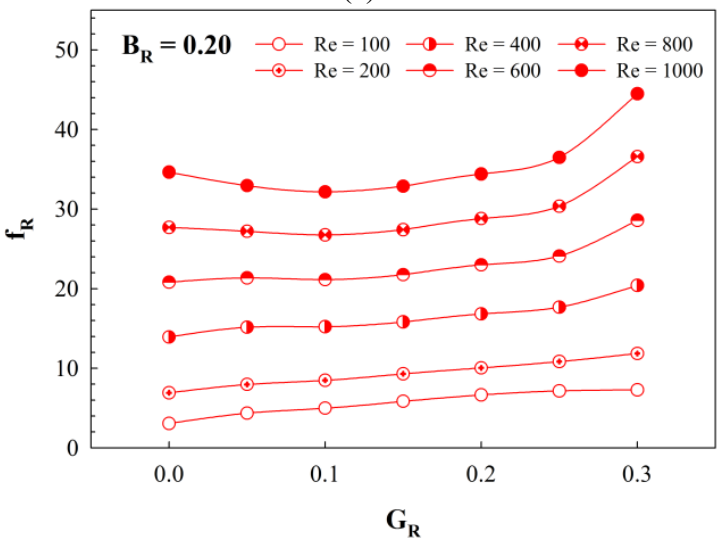

(b)

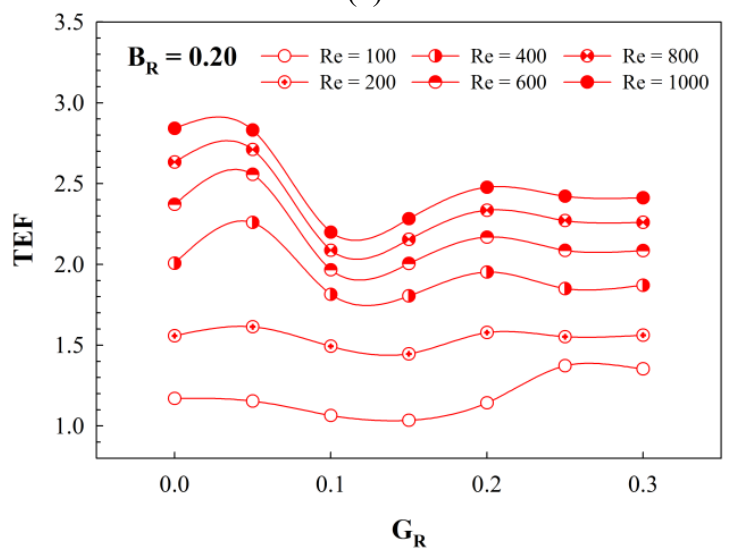

(c)

Fig. 23 (a) $\mathrm{Nu}_{R}$ vs $G_{R}$, (b) $f_{R} v s G_{R}$ and (c) TEF vs $G_{R}$ for $B_{R}=0.20$ (data at $\mathrm{G}_{\mathrm{R}}=0$ is referred from Promvonge et al. (2012) and Boonloi (2014)). 


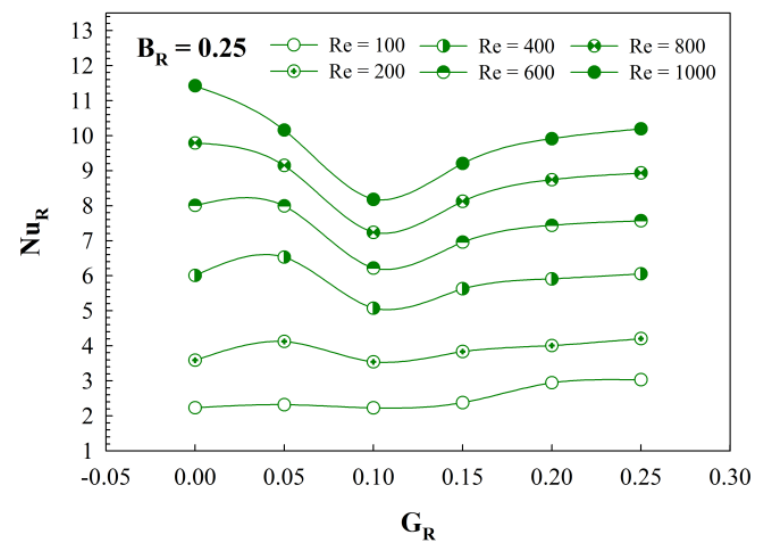

(a)

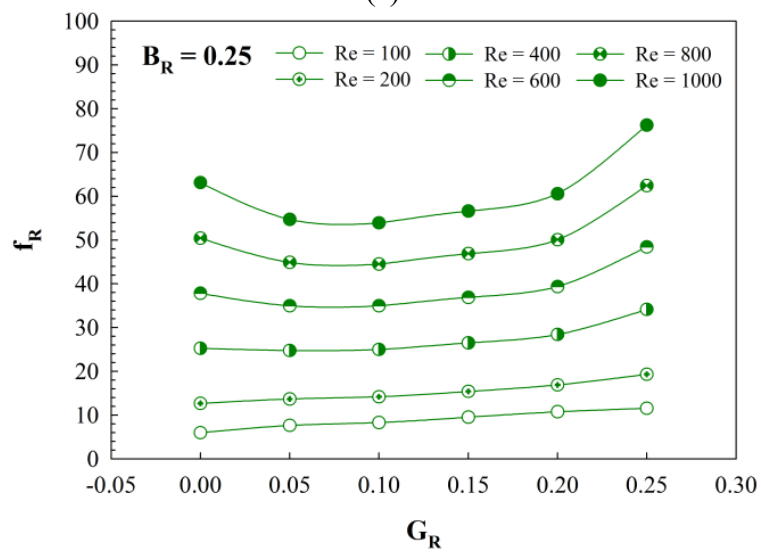

(b)

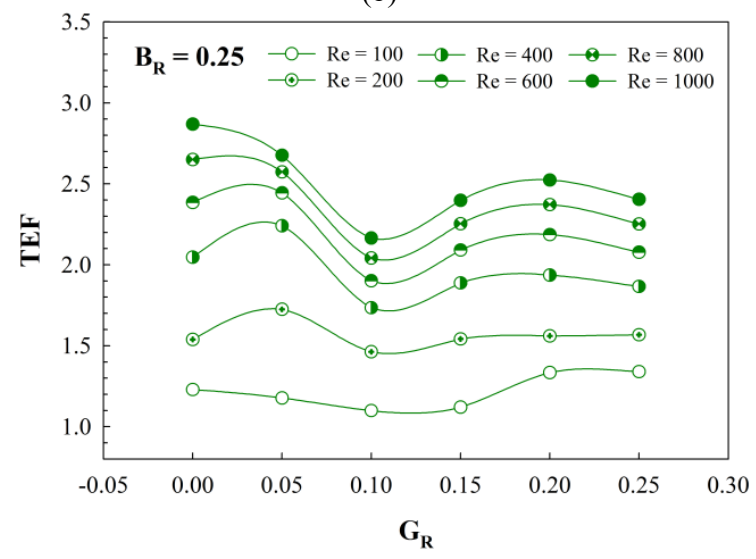

(c)

Fig. 24 (a) $\mathrm{Nu}_{R} v s \mathrm{G}_{R}$, (b) $f_{R}$ vs $G_{R}$ and (c) $T E F$ vs $G_{R}$ for $B_{R}=0.25$ (data at $\mathrm{GR}_{\mathrm{R}}=0$ is referred from Promvonge et al. (2012) and Boonloi (2014)).

The greatest TEF is about 2.68 which is detected at $\mathrm{G}_{\mathrm{R}}=0$ for the $\mathrm{B}_{\mathrm{R}}=$ 0.30 of the V-baffle. The TEF is found to be in range $1.17-2.68,1.21$ $-2.49,1.10-2.23,1.23-2.50$ and $1.32-2.33$ for $G_{R}=0,0.05,0.10$, 0.15 and 0.20 , respectively, at $B_{R}=0.30$.

\section{CONCLUSION}

Numerical predictions on heat transfer behavior and flow topology in the square channel placed with $\mathrm{V}$-baffle at various gap spacing ratios are examined. The influences of $\mathrm{BR}_{\mathrm{R}}$ and $\mathrm{GR}_{\mathrm{R}}$ for the $\mathrm{V}$-baffle are investigated for the laminar regime, $\mathrm{Re}=100-1000$. The mechanisms in the heating section inserted with V-baffle are reported in form of flow and heat transfer characteristics. The thermal performance analysis in the test section is also concluded with the plots of $\mathrm{Nu}_{R}, \mathrm{f}_{\mathrm{R}}$ and TEF.
The main outcomes of the present investigation can conclude as follows;

The addition of the V-baffle in the square duct can change the flow and heat transfer structure. The vortex flow is found in all examples. The vortex flow disturbs the thermal boundary layer near the channel walls. The thermal boundary layer disturbance is an important factor for heat transfer rate and thermal performance augmentations.

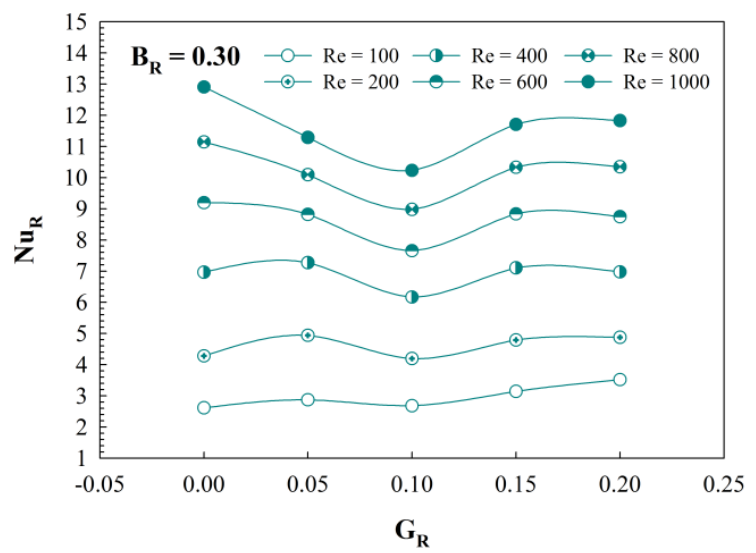

(a)

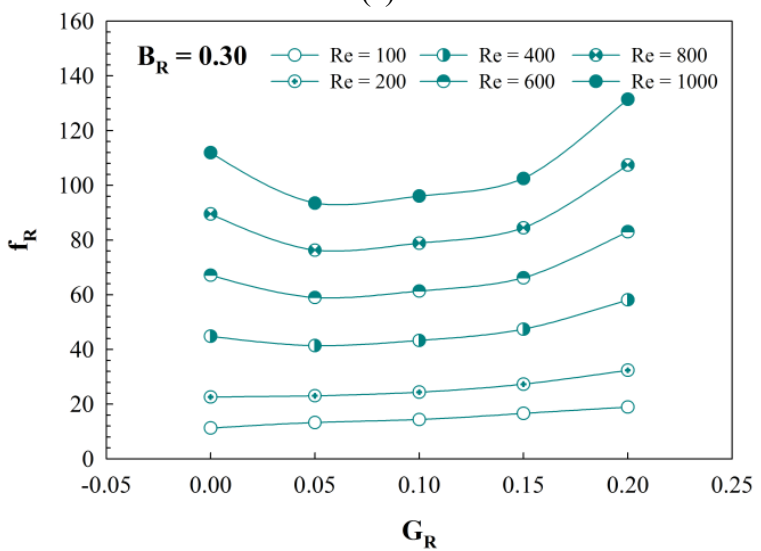

(b)

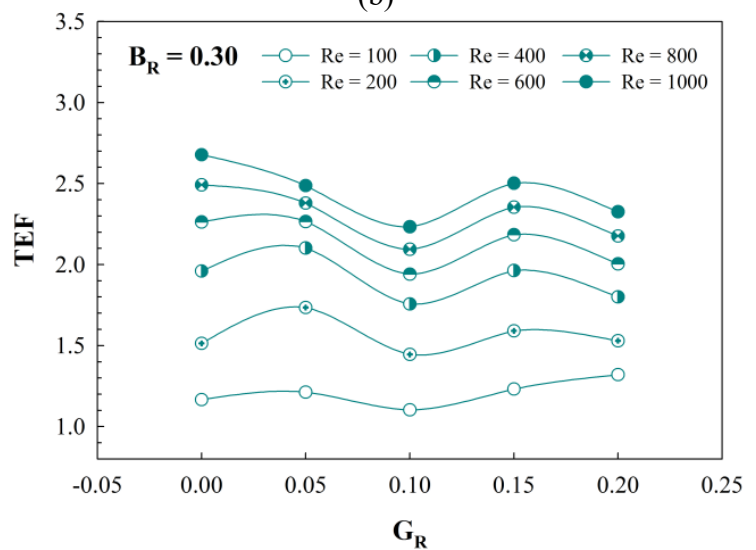

(c)

Fig. 25 (a) NuR vs $G_{R}$, (b) fR vs $G_{R}$ and (c) TEF vs $G_{R}$ for $B_{R}=0.30$ (data at $\mathrm{G}_{\mathrm{R}}=0$ is referred from Promvonge et al. (2012) and Boonloi (2014)).

The different flow and heat transfer configurations is clearly found when changed the gap spacing ratio. The gap spacing ratio has effect for the increment or reduction of the heat transfer rate and friction loss, and also influences for the distribution of the local Nusselt number ratio of the channel wall. Some values of the $\mathrm{G}_{\mathrm{R}}$ can help to be a better heat transfer distribution. 
In the real system, the gap spacing around 5\% is frequency found when inserted the V-baffle in the heat exchanger. The insertion of the baffle in the middle of the square channel is an uncomplicated method for the installation, but for some case, especially, at high $\mathrm{B}_{\mathrm{R}}$ may lead to very large pressure loss.

For suggestion, at low $B_{R}\left(B_{R}=0.05-0.15\right)$ the gap spacing ratio around $5-10 \%$ is an optimal condition for the heating system placed with V-baffle. At high $\mathrm{B}_{\mathrm{R}}(>0.15)$, the installation of the V-baffle on the channel wall $\left(\mathrm{G}_{\mathrm{R}}=0\right)$ is the best choice for the heat exchanger system.

\section{ACKNOWLEDGEMENTS}

The funding of this work is supported by King Mongkut's Institute of Technology Ladkrabang research funds (contract no. KREF046006). The authors would like to thank Assoc. Prof. Dr. Pongjet Promvonge, KMITL for suggestions.

\section{NOMENCLATURE}

$B_{R} \quad$ flow blockage ratio

b baffle height, $\mathrm{m}$

$\mathrm{D}_{\mathrm{h}} \quad$ hydraulic diameter of the channel, $\mathrm{m}$

f friction factor

$f_{R} \quad$ friction factor ratio

g gap spacing, $m$

$\mathrm{G}_{\mathrm{R}} \quad$ gap spacing ratio

$\mathrm{H} \quad$ channel height, $\mathrm{m}$

$\mathrm{h}$ convective heat transfer coefficient, $\mathrm{W} \mathrm{m}^{-2} \mathrm{~K}^{-1}$

$\mathrm{k}$ thermal conductivity, $\mathrm{W} \mathrm{m}^{-1} \mathrm{~K}^{-1}$

$\mathrm{P} \quad$ periodic length or pitch spacing, $\mathrm{m}$

$\mathrm{Nu} \quad$ Nusselt number

NuR Nusselt number ratio

$\mathrm{p} \quad$ static pressure, $\mathrm{Pa}$

Pr Prandtl number $(\operatorname{Pr}=0.707)$

Re Reynolds number

$\mathrm{T}$ temperature, $\mathrm{K}$

$u_{i} \quad$ velocity in $x_{i}$-direction, $\mathrm{m} \mathrm{s}^{-1}$

$\bar{u} \quad$ mean velocity in channel, $\mathrm{m} \mathrm{s}^{-1}$

Greek letter

$\alpha \quad$ angle of attack, degree

TEF thermal enhancement factor

$\rho \quad$ density, $\mathrm{kg} \mathrm{m}^{-3}$

Subscript

in inlet

$0 \quad$ smooth tube

pp pumping power

\section{REFERENCE}

Boonloi, A., 2014, "Effect of Flow Attack Angle of V-Ribs Vortex Generators in a Square Duct on Flow Structure, Heat Transfer, and Performance Improvement," Modelling and Simulation in Engineering, 1. Article ID 985612, 11 pages.

http://dx.doi.org/10.1155/2014/985612

Boonloi, A., and Jedsadaratanachai, W., 2014, "Thermal Performance Analysis and Empirical Correlations for Laminar Forced Convection over 30॰ V-Baffled Square Channel," Advances in Mechanical Engineering, Article ID 930272, 16 pages.

http://dx.doi.org/10.1155/2014/930272

Boonloi, A., and Jedsadaratanachai, W., 2016, "Numerical Investigation on Turbulent Forced Convection and Heat Transfer Characteristic in a Square Channel with Discrete Combined Vbaffle and V-orifice," Case Studies in Thermal Engineering, 8, 226235.

https://doi.org/10.1016/j.csite.2016.07.003

Jedsadaratanachai, W., and Boonloi, A., 2014, "Effects of Blockage Ratio and Pitch Ratio on Thermal Performance in a Square Channel with $30^{\circ}$ Double V-baffles," Case Studies in Thermal Engineering, 4, 118-128.

https://doi.org/10.1016/j.csite.2014.08.002

Jedsadaratanachai, W., Jayranaiwachira, N., and Promvonge, P., 2015, "3D Numerical Study on Flow Structure and Heat Transfer in a Circular Tube with V-baffles," Chinese Journal of Chemical Engineering, 23, 342-349.

https://doi.org/10.1016/j.cjche.2014.11.006

Kumar, R., Chauhan, R., Sethi R., and Kumar, A., 2017, "Experimental Study and Correlation Development for Nusselt number and Friction Factor for Discretized Broken V-pattern Baffle Solar Air Channel," Experimental Thermal and Fluid Science, 81, 56-75. https://doi.org/10.1016/j.expthermflusci.2016.10.002

Kumar, R., Sethi, M., Chauhan, R., and Kumar, A., 2017, "Experimental Study of Enhancement of Heat Transfer and Pressure Drop in a Solar Air Channel with Discretized Broken V-pattern Baffle," Renewable Energy, 101, 856-872.

https://doi.org/10.1016/j.renene.2016.09.033

Kumar, R., Kumar, A., Chauhan, R., and Sethi, M., 2016, "Heat Transfer Enhancement in Solar Air Channel with Broken Multiple Vtype Baffle," Case Studies in Thermal Engineering, 8, 187-197. https://doi.org/10.1016/j.csite.2016.07.001

Li, J.L., Tang, H.W., and Yang, Y.T., 2018, "Numerical Simulation and Thermal Performance Optimization of Turbulent Flow in a Channel with Multi V-shaped Baffles," International Communications in Heat and Mass Transfer, 92, 39-50.

https://doi.org/10.1016/j.icheatmasstransfer.2018.02.004

Promvonge, P., 2010, "Heat Transfer and Pressure Drop in a Channel with Multiple $60^{\circ}$ V-baffles," International Communications in Heat and Mass Transfer, 37, 835-840.

https://doi.org/10.1016/j.icheatmasstransfer.2010.04.003

Promvonge, P., and Kwankaomeng, S., 2010, "Periodic Laminar Flow and Heat Transfer in a Channel with $45^{\circ}$ Staggered V-baffles," International Communications in Heat and Mass Transfer, 37, 841-849. https://doi.org/10.1016/j.icheatmasstransfer.2010.04.002

Promvonge, P., Jedsadaratanachai, W., Kwankaomeng, S., and Thianpong, C., 2012, "3D Simulation of Laminar Flow and Heat Transfer in V-baffled Square Channel," International Communications in Heat and Mass Transfer, 39, 85-93.

https://doi.org/10.1016/j.icheatmasstransfer.2011.09.004 